\title{
Misión Y CRUZADA EN EL PENSAMIENTO DE RAMON LLULL (1232-1316), UNA CUESTIÓN SIN ZANJAR
}

\author{
Ignacio CABello Llano ${ }^{1}$ \\ Universidad Autónoma de Madrid
}

Recibido: 17 de diciembre de 2019

Aceptado: 28 de abril de 2020

\begin{abstract}
Resumen
En este artículo presentamos un estado de la cuestión (revisión bibliográfica y esbozo de una posible línea a seguir) acerca de las ideas de misión y cruzada y su interrelación (la manera en que se conjugan ambos conceptos, aparentemente contradictorios o excluyentes) en el pensamiento filosófico, político y misionero del mallorquín Ramon Llull (1232-1316). Tras explicar los principales puntos fuertes y débiles de cada uno de los enfoques historiográficos, llegamos a la conclusión de que un estudio profundo, holístico y unitario del pensamiento de Llull podría iluminar la cuestión de la misión y la cruzada superando viejos esquemas dualistas y alcanzando una comprensión más adecuada del problema.
\end{abstract}

\section{Palabras clave}

Ramon Llull, cruzada, misión, literatura apologética y diálogo interreligioso, relaciones cristianismoislam en la Edad Media.

\begin{abstract}
In this article we present a state of the art - bibliographical review and outline of a possible line of research - about the ideas of mission and crusade and their interrelation - the way in which both concepts, apparently contradictory or excluding, are conjugated - in the philosophical, political and missionary thought of the Mallorcan Ramon Llull (1232-1316). After explaining the main strengths and weaknesses of each of the historiographic approaches, we have come to the conclusion that a deep, holistic and unitary study of Llull's thought could illuminate the question of mission and crusade, overcoming old dualist schemes and achieving a more adequate understanding of the problem.
\end{abstract}

\section{Keywords}

Ramon Llull, crusade, mission, apologetic literature and interreligious dialogue, Christian-Muslim relations in the Middle Ages.

\section{Riassunto}

In questo articolo presentiamo uno stato dell'arte (rassegna bibliografica e schema di una possibile linea di ricerca da seguire) sulle idee di missione e crociata e la loro interrelazione (il modo in cui entrambi i concetti, apparentemente contraddittori o esclusi, sono coniugati) nel pensiero filosofico,

\footnotetext{
1 Universidad Autónoma de Madrid, Campus de Cantoblanco. Facultad de Filosofía y Letras. Correo electrónico: ignacio.cabello@uam.es. OrciD: https://orcid.org/0000-0003-1200-6605.
} 
politico e missionario del maiorchino Raimondo Lullo (1232-1316). Dopo aver spiegato i principali punti di forza e di debolezza di ciascuno degli approcci storiografici, siamo giunti alla conclusione che uno studio profondo, olistico e unitario del pensiero di Lullo potrebbe illuminare la questione della missione e della crociata, superando vecchi schemi dualistici e raggiungendo una comprensione più adeguata del problema.

\section{Parole chiave}

Raimondo Lullo, crociata, missione, letteratura apologetica e dialogo interreligioso, rapporti cristianimusulmani nel Medioevo.

\section{Ramon Llull ${ }^{2}$ y el islam}

\subsection{Sueños de conversión}

El tema de Llull y el islam ha sido ampliamente estudiado y resulta — se ha dicho"demasiado obvio", pero, aun así, sigue despertando hoy en día el interés de multitud de investigadores. Ello se debe, creo, a un doble factor: por un lado, a la fascinación que supone estudiar el pensamiento tan original de alguien que vivió hace más de setecientos años y, por otro, a la conciencia de que estudiar las relaciones entre las grandes identidades religiosas en el mundo premoderno puede ser enriquecedor para nuestra comprensión de las mismas y de gran provecho para el planteamiento de los cauces por los que puede discurrir una mejor relación entre ellas en la actualidad. Además, los planteamientos del mallorquín acerca de cómo afrontar el 'problema del infiel' siguen ofreciendo hoy posibilidades de ser revisados y conducidos hacia puertos diferentes, superando los escollos en los que la investigación ha encallado en el pasado.

En el siglo XIII en el que nació nuestro personaje, la cristiandad experimentó una formidable expansión a todos los niveles: fue la época de las ciudades y el comercio; de las universidades y las catedrales; de la consolidación de las monarquías y el desarrollo

\footnotetext{
${ }^{*}$ Quisiera agradecer a los revisores anónimos por enriquecedoras sus sugerencias. He procurado introducir a lo largo del texto correcciones (esp. apartados 2.2 y 2.3) y notas (esp. notas 30 y 68) entrando en diálogo con sus comentarios.

** Abreviaturas de colecciones de obras de Llull citadas a lo largo del trabajo: MOG = Raymundi Lulli Opera omnia, ed. I. Salzinger, 8 vols. (Mainz, 1721-42; reimpr. Frankfurt, 1965); ORL = Obres de Ramon Lull, edició original, 21 vols. (Palma, 1906-50); Obras = Obras de Ramón Lull, ed. J. Rosselló, pr. M. Obrador i Bennassar, 3 vols. (Palma, 1901-1903) y ROL = Raimundi Lulli Opera Latina (Palma, 1959-67 y Turnhout, d. 1975). El resto de obras de Llull se citarán por el nombre de su editor y la fecha de edición, y aparecerá la referencia completa en la bibliografía.

2 La grafía de su nombre ha variado a lo largo del tiempo: Raymundus/Raimundus Lullus/Lullius; Raimundo Lulio; Raymond Lulle; Lul, Luyl, Lull en romance, etc. Nos adherimos a la forma catalana contemporánea preferida por la historiografía actual: 'Ramon Llull'.

3 "L'enunciat del tema resulta massa obvi. Resultaria més bé difícil el contrari: pensar Ramon Llull sense cap referència a l'Islam" (GAYÀ EstelRich, "Ramon Llull i l'Islam...," p. 1). No le falta razón, pues "su empresa islámica llena toda su vida; [...] su vida es un tejido de hechos islámicos" (GARcías PALOU, Ramón Llull y el islam, pp. 15-16).
} 
jurídico, político e institucional, y también de las cruzadas y las misiones. El occidente cristiano trascendió sus fronteras y se dilató, como nunca antes, más allá de las mismas, viéndose obligado a hacer frente a una realidad que no solo representaba una amenaza política, económica y territorial, sino también religiosa: el islam. En el extremo occidental del Mediterráneo, los reinos cristianos peninsulares, con Castilla y Aragón a la cabeza, protagonizaron, a partir de la batalla de las Navas de Tolosa (1212) y a lo largo de buena parte de la centuria, un espectacular avance hacia el sur, y a medida que reconquistaban ${ }^{4}$ territorios antes dominados por la Media Luna hubieron de enfrentarse al problema de la asimilación en sus reinos de población no cristiana - judíos y, sobre todo, musulmanes-. Al mismo tiempo, a lo largo del Duecento, el dominio cristiano en Oriente fue menguándose hasta desaparecer definitivamente en 1291 con la caída de San Juan de Acre. Por todo ello, el siglo XIII vio un florecer de muy diversas estrategias para abordar el 'problema' del islam: misión, cruzada, reconquista de Tierra Santa, disputa apologética, refutación teológica, predicación, martirio, etc. Todo ello son movimientos de una misma sinfonía que resonaba en toda la cristiandad y cuyo leitmotiv era la exaltación y propagación de la fe y la defensa de la Cruz. Es precisamente en este contexto del "sueño de conversión del siglo XIII" en el que hemos de situar a Ramon Llull: nacido en la Mallorca recién reconquistada ${ }^{6}$, vivió de primera mano el problema de la incorporación e integración de la población musulmana local (un $40 \%$ ) en la nueva sociedad cristiana?.

En torno a los treinta años, tras una vida de cierta mundanidad ${ }^{8}$, Llull experimentó una profunda y radical conversión que suscitó en él el deseo de amar y servir a Dios,

\footnotetext{
4 Aunque el concepto de reconquista está últimamente siendo discutido (GARCía SANJUÁn, "La persistencia del discurso nacionalcatólico..."; "Rejecting al-Andalus, exalting the Reconquista..." o "Cómo desactivar una bomba historiográfica..."), me sumo a la opción que considero más razonable: aquella que aboga por la utilización del término entendido como ideología de guerra, como discurso o aparato ideológico desarrollado y utilizado por los poderes cristianos peninsulares para legitimar y sacralizar, con todas las consecuencias que de ello se derivan, la guerra contra al-Andalus (BRonisch, Reconquista y Guerra Santa...; García Fitz, "La Reconquista..." y "Crítica e hipercrítica...”, y Ayala Martínez, "Órdenes militares y guerra santa..." y "La Reconquista: ¿ficción o realidad historiográfica?").

Burns, "Christian-Islamic Confrontation in the West: The Thirteenth-Century-Dream of Conversion". 6 Para la cuestión de la conquista y la reconquista en Aragón, véase ALVIRA, "Conquista y reconquista..." 7 La importancia del contexto es clara: Mallorca, en la periferia de la cristiandad y al margen de los reconocidos centros intelectuales; situada en un lugar intermedio, perfecto punto de partida para un misionero que desease viajar a los centros de poder político y religioso cristianos y al norte de África; caracterizada por una pluralidad cultural y religiosa que implicaba una situación de frontera que no se correspondía del todo con el modelo social del resto de la cristiandad y que permitió a Llull entrar en contacto desde su infancia con una comunidad musulmana que representaba el $40 \%$ de la población mallorquina. Véase Dufource, "La Couronne d'Aragon..." y "La Méditerranée et le Christianisme..."; Batllori, Ramon Llull en el món del seu temps, "Introducción" e "Introducción: Ramon Llull”; Hillgarth, "La vida i la significació..." y "Vida i importancia de Ramon Llull...", y Domínguez ReborRas, Ramon Llull..., pp. 70-97.

8 Esta mundanidad ha de ser entendida no tanto como una vida lujuriosa y mujeriega (tópico literario que Llull subraya en la construcción de su personaje), sino como una vida que no estaba presidida por la búsqueda de Dios - finalidad última del hombre, como veremos - sino por la búsqueda de la satisfacción de aspiraciones y deseos materiales.
} 
consagrando su vida ${ }^{9}$ y su pluma ${ }^{10}$ a un triple objetivo: procurar la conversión de los infieles hasta dar la vida por Cristo si fuera necesario; escribir un libro, el mejor del mundo, contra los errores de los infieles, y promover la fundación de monasterios de formación misionera ${ }^{11}$. Las dos grandes preocupaciones o ideales que presidieron su vida y su obra fueron la reforma moral de la societas christiana y la conversión de los infieles al cristianismo — con especial hincapié en los musulmanes, que suponían un problema social mayor- Estos dos ideales (que, como veremos, estaban al servicio de un ideal superior: que el Dios cristiano fuese servido y alabado por todo el mundo y en ello la humanidad alcanzase y se realizase en la finalidad para la cual fue creada) y los medios concretos que propuso para llevarlos a cabo (entre los cuales se hallan los planteamientos de misión y cruzada), le costaron la incomprensión de sus contemporáneos y el calificativo de pensador idealista o utópico por parte de muchos de quienes lo han estudiado. No obstante, en su complejo sistema de pensamiento encontramos conceptos y elementos de una riqueza extraordinaria para ahondar en el conocimiento de las relaciones entre cristianismo e islam en la Edad Media, cuestión, que, por otra parte, nunca perderá interés y actualidad.

Tras su conversión, siguen nueve años de vida contemplativa y de estudio en Mallorca (c. 1265-1274), al cabo de los cuales se produjo la iluminación y el 'descubrimiento' de un nuevo Arte de encontrar la verdad, un sistema filosófico-teológico que habría de constituir una nueva ciencia que abarcase y aunase todas las existentes y el método definitivo para lograr la conversión de los infieles. Desde el momento de la 'recepción iluminativa', Ramon reformuló una y otra vez su Arte con la esperanza de que su revolucionario método fuese entendido y escuchado por los intelectuales europeos, apoyado

9 Entre las biografías de Llull de mayor calidad cabe señalar las siguientes: CARreras I ArTAU, Historia de la filosofía..., pp. 237-256; Hillgarth, Ramon Llull and Lullism..., pp. 1-134; GayÀ Estelrich, Ramon Llull; Bonner y BADIA, Ramon Llull. Vida, pensament i obra; VEGA EsQUERRA, Ramon Llull y el secreto de la vida; Domínguez Reboiras y Gayà Estelrich, "Life”; Villalba i Varneda, Ramon Llull y Domínguez ReBoiras, Ramon Llull. El mejor libro.... Las fuentes para reconstruir su vida son la Vita coetanea (ROL VIII: 259-309), un relato autobiográfico que Llull dictó en 1311 a los monjes de la cartuja de Vauvert y que serviría como carta de presentación ante el concilio de Vienne (Domínguez ReBoiras, "Idea y estructura de la Vita..." y GAYÀ EstelRich, "Ramon Llull i l'Islam...”); las menciones autobiográficas en sus obras, que han de ser interpretadas con cierta cautela, diferenciando el Ramon real del Ramon personaje (BADIA, "Ramon Llull: Autor i Personatge"); la información del lugar y fecha de conclusión de sus obras firmadas a partir de 1294; el Electorium paruum seu Breuiculum elaborado por su discípulo Thomas Le Myésier (ROL Supplementum Lullianum I), y un conjunto de documentación sobre las actividades y vida de Ramon Llull (Garcías Palou, El miramar..., pp. 317-342 y Hillgarth, Diplomatari...).

10 Los especialistas cuentan hasta 265 obras auténticas conservadas de Llull, de temática y tipología variadas, desde tratados de ciencias, lógica y filosofía, hasta obras de carácter teológico, catequético-doctrinal y apologético, discurriendo también por los caminos de la novela, la dialógica y la poesía ejemplares y por los de la mística contemplativa. Véase un catálogo en Domínguez Reborras, "Works" y Ramon Llull. El mejor libro..., así como la completísima Base de Dades Ramon Llull de la Universitat de Barcelona, disponible en www.ub.edu/llulldb/index.asp.

11 La de Llull es una "filosofía de la conversión", es decir, "la filosofía del converso que quiere convertir" (CArreras i Artau, Historia de la filosofía..., p. 635). Sobre su conversión, véase Colomer I Pous, "Autorretrato de Ramon Llull...”; GAYÀ EsTELRICH, “«De conversione sua ad poenitentiam»...” y VEGA ESQUERRA, Ramon Llull y el secreto... 
por los dirigentes políticos y religiosos de la cristiandad y, en definitiva, puesto en práctica por los misioneros. Convencido del potencial universal de su método d'atrobar veritat y de convertir els infeels, Llull emprendió constantes viajes en busca del apoyo de príncipes, reyes y pontífices. Inicialmente en ámbito mallorquín y aragonés, donde en 1276 consigue la fundación — con bula pontificia y la financiación por parte de Jaime II de Mallorca - del monasterio de Miramar para la formación de misioneros, a partir de 1287 comenzó a difundir sus ideas y proyectos en los centros de poder de la cristiandad: en 1287 viajó a la corte papal, aunque no obtuvo frutos por la muerte repentina de Honorio IV; entre 1287 y 1289 estuvo en París, donde se entrevistó con Felipe IV e intentó, de nuevo fallidamente, enseñar su Arte en la universidad; en 1292 presentó a Nicolás IV sus proyectos de misión y cruzada en el Liber de passagio - aunque el nuevo papa falleció prematuramente y sus propuestas nuevamente no recibieron la atención esperada, de modo que decidió partir hacia tierras islámicas para poner en práctica su teoría misionera-; en 1293, tras una crisis espiritual por el fracaso de sus proyectos y por el miedo a lo que pudiera sucederle predicando en el norte de África, emprendió su primer viaje misionero a Túnez, de donde sería expulsado al cabo de un mes; en 1294, tras predicar entre la comunidad islámica de Lucera, en Nápoles, con permiso de Carlos II de Anjou, dirigió una petición per a la conversió dels infidels a Celestino V — petitio que renovó al año siguiente, esta vez a Bonifacio VIII-; entre 1297 y 1299 estuvo en París, donde, de nuevo, no logró el reconocimiento de su obra que tanto ansiaba; en 1300 regresó a Mallorca con un permiso del monarca aragonés para predicar en las sinagogas y mezquitas de los territorios de la Corona; en 1301, al calor de las positivas - aunque finalmente falsas - noticias acerca de una posible alianza cristiano-mongola contra los egipcios, Ramon viajó al Mediterráneo oriental (Armenia Menor, Chipre y, posiblemente, Jerusalén); en 1305 presentó a Clemente V, a través del rey de Aragón, el Liber de fine, su tratado más extenso y completo de misión y cruzada; en 1307 viajó de nuevo al norte de África, esta vez a Bugía (Béjaia), donde su predicación fue un tanto más incisiva y osada, llegando a afirmar abiertamente que "la ley de los musulmanes es falsa y errónea", por lo que fue encarcelado (en la prisión, al parecer, mantuvo disputas con algunos sabios musulmanes, una de las cuales quedaría de algún modo recogida en el Liber disputationis Raimundi christiani et Homeri saraceni de 1308) y finalmente expulsado de la ciudad; en 1309 escribió su último tratado de cruzada, el Liber de acquisitione Terrrae Sanctae, dirigido a Jaime II, que en aquel momento preparaba el sitio de Almería y lideraba una fallida cruzada contra Granada; después pasó dos años en París, donde participó en la polémica antiaverroísta y donde, al parecer, su Arte tuvo una mejor recepción que en anteriores ocasiones; en septiembre de 1311 se dirigió a Vienne para asistir al concilio ecuménico, en el que presentó diez ordenaciones en las que reiteraba algunas de sus ideas y propuestas de misión y cruzada; a partir de 1312, decepcionado con el aparato político y eclesiástico de la cristiandad y con sus principales dirigentes - Felipe IV y Clemente V- Llull inició un acercamiento a Federico III de Sicilia, quien, rodeado de grupos reformistas y 
espiritualistas franciscanos, parecía más propenso a escuchar y secundar sus ideas ${ }^{12}$ y a quien propuso el Liber de participatione christianorum et saracenorum (1312); en 1314, sin ningún indicio de que se hubiesen cumplido sus expectativas acerca del monarca siciliano, Llull se embarcó de nuevo rumbo a Túnez, donde el clima político-religioso resultó ser más favorable para su predicación, fruto de la cual escribió veinticinco obras ${ }^{13}$. A partir de diciembre de 1315, fecha en que firma sus últimas obras, Llull desaparece de la historia, falleciendo en su isla natal a principios de 1316.

En las páginas que siguen estudiamos los planteamientos fundamentales de la 'filosofía de la acción' luliana para afrontar el 'problema del infiel', esto es, la particular propuesta de Llull de modo convertendi infideles, prestando atención a la manera en que se conjugan en su pensamiento conceptos aparentemente tan contradictorios como misión (evangelización, predicación y testimonio de fe en aras de la conversión de los no cristianos) y cruzada (empresa bélica proclamada o autorizada por el pontífice romano en nombre de Cristo para la recuperación de los Santos Lugares o, en un sentido más amplio, para dilatar las fronteras de la cristiandad y devolver toda la tierra a la fe en el Dios cristiano), diálogo interreligioso libre, disputa apologética y 'evangelización forzada', o deseo de paz universal y afán de conversión de todo el orbe.

\subsection{Proyectos de misión y planes de cruzada}

El sueño de que era posible lograr, por vía racional, la conversión de los infieles fue el combustible de toda una vida cuyo norte fue siempre la misión ${ }^{14}$. En efecto, Llull creyó - y estuvo plenamente convencido de ello — haber encontrado el método definitivo para lograr la conversión de todos los infieles al cristianismo, objetivo al que consagró su vida. Llull pretendía convertir a los no cristianos mediante el convencimiento racional de que la religión (lig) cristiana era magis bona, magis magna et etiam magis vera, y su método misionero, expuesto y desarrollado en muchas de sus obras y presente en todas ellas, consistía en la búsqueda de un terreno común para el diálogo (construido sobre los presupuestos comunes a las tres religiones abrahámicas: la razón como capacidad intrínseca al ser humano; la creencia en un Dios único al que cabe atribuirle en grado máximo una serie de dignidades o atributos divinos esenciales, y un concepto

\footnotetext{
12 Sobre las relaciones entre Ramon y Federico III, véase Hillgarth, Ramon Llull an Lullism..., pp. 130 y ss.; Garcías Palou, "El candidato...” y Ramón Llull y el islam, pp. 217-228; Musco y Romano (eds.), Il Mediterraneo del '300... y Domínguez Reboiras, Ramon Llull. El mejor libro..., pp. 287-291 y 301-334.

13 Sobre este contexto favorable a Llull, véase DufourcQ, "La Couronne d'Aragon...” y "La Méditerranée et le Christianisme..."; Hillgarth, Ramon Llull and Lullism..., pp. 130-134; Urvoy, Penser l'Islam..., pp. 235-238 y Garcías Palou, Ramón Llull y el islam, pp. 233-240. El sultán Ibn al-Lihyāni, a quien los reyes de Aragón y Sicilia habían ayudado a hacerse con el poder y que mostraba una generosa actitud de tolerancia hacia los cristianos, estuvo cerca de convertirse al cristianismo (Lower, "Ibn al-Lihyani...").

14 Sobre el método misionero de Llull se ha escrito muchísimo. Remito tan solo a GARcías PALOU, Ramón Llull y el islam; Colomer i Pous, "La actitud compleja..." y "El Diàleg interreligiós...", GayÀ EstelRich, "Ramon Llull, il suo impegno missionario", "Introducción”, Raimondo Lullo... y "Ramon Llull i l'Islam..." y CALPe Melendres, “La relación intelecto-voluntad en el método misionológico luliano...”.
} 
ejemplarista más o menos platonizante de Dios y de las relaciones entre el Creador y la creación; es decir, Dios en la unidad dinámica de sus dignidades) y en la promoción de encuentros y disputas entre sabios bene litterati de cada religión que pudiesen exponer sus principios de su propia fe y argumentar a su favor racionalmente (per rationes necessarias y no per auctoritates o argumentos de autoridad doctrinal-textual extraídos del propio texto sagrado, lo cual frenaba o impedía el diálogo fructífero), sobre la base de un entendimiento mutuo y un conocimiento de la religión 'del otro' que elevase las disputas por encima de los falsos prejuicios y conceptos que se habían formado unos de otros. Llull insistió mucho en la necesidad de que las disputas apologéticas se hiciesen sobre la base de un conocimiento adecuado y real de la religión del oponente, pues, de no ser así, cualquier intento de convertir al otro se vería abocado al fracaso. A este fin se crearían tres tipos de escuelas o centros con fines misioneros: un primer tipo $-\mathrm{y}$ el único hecho realidad, en Miramar - eran los centros especializados en los que los futuros misioneros cristianos estudiarían las lenguas ${ }^{15}$, creencias, formas de pensar y otros elementos culturales y religiosos de los infieles; un segundo eran espacios en los que se tendría que producir un intercambio de sabios cristianos y de otras religiones como el propuesto en el Liber de participatione, a fin de que unos y otros lograsen un conocimiento adecuado de las creencias y razones de la religión 'del otro'; y un tercer tipo eran escuelas a las que los judíos y musulmanes deberían acudir obligatoriamente y en las que se les mostraría el contenido de la fe cristiana.

En otras palabras: Llull confiaba en que, con las herramientas adecuadas (el conocimiento de las lenguas, culturas y religiones de los infieles; y la instrucción de éstos en el contenido de la fe cristiana), sería posible convencer racionalmente ${ }^{16}$ de la superioridad de

15 Sobre la insistencia de Llull en que los misioneros estudiasen árabe (hasta veintinueve veces), vid. Garcías Palou, El Miramar... y Ramón Llull y el islam, pp. 107-140; Brummer, "L'enseignement...” y "Una qüestió debatuda...”; Domínguez Reboiras, "Ramon Llull, "catalán de Mallorca...”; Perarnau i Espelt, "La còpia manuscrita..." y Roviró Alemany, "Ramon Llull y los Studia linguarum". Sobre el estudio del árabe en la Edad Media, vid. Monneret de Villard, Lo studio dell'islam...; Coll, "Escuelas...(Periodo Raymundiano)", "Escuelas...(Período postraymundiano)", "San Raymundo de Peñafort..."; Cortabarría Beitia, " Connaissance de l'Islam..." y "Los «Studia Linguarum»..."; RoncAglia, "I frati minori e lo studio..."; Urvoy, "Les Musulmans et l'usage de la langue árabe"; Lourido DíAz, "El estudio de la lengua árabe" y GiménEz ReílLo, "El árabe como lengua extranjera...".

16 La cuestión de la relación entre fe y entendimiento afecta a lo más hondo de su estrategia frente a los musulmanes. Llull tiene la certeza de que la verdad triunfa y se impone por su propio peso y que ningún ser humano de buena fe, razonando libre y desapasionadamente, puede dejar de adherirse a la fe cristiana si esta se le presenta racionalmente mediante fórmulas lógicas e irrefutables que denomina 'razones necesarias' — sus 'armas intelectuales'- Así, Llull se separa radicalmente de la estrategia apologética seguida por sus predecesores y coetáneos: por un lado, rechaza las disputas basadas en autoridades textuales - en estas, la fuerza del argumento la daba el hecho de que estaban basados en la Biblia, la Torah o el Corán - porque derivan en discusiones interminables y porque los interlocutores infieles jamás aceptarían los argumentos de autoridad doctrinal-textual de los cristianos; por otro lado, critica severamente a los misioneros que pretendían convertir a los musulmanes sin demostrarles racionalmente la verdad de la fe cristiana. En cambio, propone disputar con los infieles a partir de unos presupuestos que considera comunes a las tres ligs y exclusivamente mediante argumentaciones lógico-racionales, pues está convencido de que, mediante una exposición lógica de rationes necessariae, el infiel bien dispuesto y que admita la existencia de Dios y de sus principales atributos no puede racionalmente rechazar los 
la fe cristiana a los sabios de otras religiones y que su conversión arrastraría al pueblo a hacer lo mismo. Así, para Llull, la misión en aras de la conversión de los infieles era un acto de amor, resultado del primigenio amor de Dios por la humanidad y cuya máxima expresión sería el martirio; un acto de libertad, ya que en ningún caso se debe imponer ninguna creencia por la fuerza, y - muy importante, porque aquí radica uno de los puntos más originales de la propuesta luliana - un acto de inteligencia, pues para creer es necesario entender ${ }^{17}$.

En sus obras defendió sistemáticamente la misión mediante armas intelectuales (la predicación racional per rationes necessarias) ${ }^{18}$ y espirituales (el testimonio y el martirio, según la manera de Jesús y los apóstoles) ${ }^{19}$ como la vía más eficaz y más acorde

dogmas cristianos ni aceptar una aserción contraria a los mismos como necesariamente verdadera y, por otra parte, de que el fiel cristiano puede resolver satisfactoriamente las objeciones dirigidas contra los dogmas cristianos y dar en favor de estos razones quas infideles destruere non possint. Llull está, por tanto, rompiendo y superando la distinción entre las verdades religiosas accesibles a la razón — los preambula fidei- y las que sólo pueden ser conocidas por fe, ampliando así el horizonte de la controversia apologética. Todos los autores coinciden en considerar este punto de la predicación como ars demonstrativa mediante rationes necessariae como uno de los elementos más característicos de su estrategia frente al islam: gracias a su confianza en la razonabilidad y la demostrabilidad de la verdad cristiana, Llull es verdaderamente revolucionario y rompedor con respecto a la literatura apologética tradicional y de su tiempo. Sobre el racionalismo luliano y las rationes necessariae, vid. CARreras i Artau, Historia de la Filosofía..., pp. 335-345 y 514-523; Mendía, "En torno a las razones necesarias..."; Garcías Palou, "San Anselmo...", "Las «rationes necessariae»..." y Ramón Llull y el islam, pp. 141-171; EIJo Garay, "Las «rationes necessariae»..." y "Las dignidades lulianas"; GraCIA, "La doctrina luliana de las razones necesarias..."; STÖHR, "Las «rationes necessariae»..."; Colomer I Pous, "Ramón Llull y su actitud frente al Islam y al Judaísmo...", "El pensament ecumènic...", "El pensament de Ramon Llull...", "La actitud compleja..." y "El Diàleg interreligiós..."; COFresI, "Reason and Revelation"; ARTus, "The Philosophical Understanding..."; BADIA, Teoria i pràctica..., pp. 121-149; BONNER, "Reducere auctoritates...", The Art and Logic y "La disputa interreligiosa..."; Domínguez ReborRas, “«Moltes novelles raons»...” y "El proyecto luliano de predicación..."; Gayà Estelrich, Raimondo Lullo... y "Ramon Llull i l'Islam..."; PARdo Pastor, "En torno a las rationes necessariae...", "Filosofía y teología...", “«Nisi crederitis, non intelligetis»...” у "Ramon Llull y el ars conuertendi..."; Hames, "Quia nolunt dimittere..." y Fidora, "L'art de convertir...". A menudo se le compara con Ramon Martí (LongPRé, "Le B. Raymond Lulle...”; Lavajo, "Un confronto metodológico...” y "The apologetical method...”; Colomer i Pous, "Ramón Llull y Ramón Martí”; Bonner, "L’apologètica de Ramon Martí i Ramon Llull..." y Fidora, "Ramon Martí in context...”).

17 Sugranyes de Franch, Raymond Lulle..., pp. 55-57, "Els projectes...", p. 276 y "La obra misional...", pp. 46-47.

18 El ejército intelectual imaginado por Llull irá armado de rationes necessariae, como queda reflejado en sus dos tratados de cruzada más importantes: "Adhuc sit de praedicto ordine unus magister in theologia, qui habeat secum et de ordine suo uiros sanctos et deuotos, qui addiscant diuersas linguas in aliquo loco uel locis continue, scilicet arabicam linguam, persescam et comanicam, et guscam et alias linguas scismaticas. Isti sint scientes in teologia et philosophia, qui habeant etiam deuotionem mori propter Deum et praedicare uerbum Dei per uniuersum mundum. Habeant etiam libros [...] in quibus sint rationes necessariae ad destruendum omnes obiectiones infidelium, per quas etiam fieri possint positiones, quas infideles destruere non possint" (Quomodo Terra Sancta recuperari potest [Liber de passagio], 1292; ROL XXVIII: 328-329) y "damus ita cogentes rationes, quod intellectus humanus contra ipsas non potest contrarium consentire" (Liber de fine, 1305; ROL IX: 256).

19 Reproduzco tres de los textos más famosos al respecto: "[...] Molts cavallers veg que van en la sancta terra doutramar e cuyden aquella conquerre per forsa $d$ armes. On, com ve a la fi tots si consumen sens que no venen a fi de so ques cuyden. On, par me, Sènyer, que lo conqueriment daquella sancta terra nos 


\section{con el espíritu cristiano y evangélico para convertir a los infieles, propagar la fe y recuperar Tierra $\mathrm{Santa}^{20}$, al tiempo que condenó severamente el modo en que se esta-}

deja conquerir sinó per la manera on la conquesés vos els vostres apòstols, qui la conquerís ab amor e ab oracions e ab escampament de lagremes e de sanc. Con lo sant sepulcre, Sènyer, e la sancta terra doutramar par ques deja conquerre per predicacio mills que per forsa darmes, ¡faense a avant, Sènyer, los sants cavallers religioses e guarnesquense del senyal de la creu, e umplense de la gràcia del Sant Espirit, e vajen preicar veritat de la vostra passió als infeels, e escampen per la vostra amor totes les aigües de lurs ulls e tota la sanc de lurs cors, axí com vos feés per amor dells. Tant cavaller e tant noble príncep es anat en la terra doutramar, Sènyer, per conquerre, que si a vos plagués la manera, be par ver que la aguessen tolta als sarrayns qui mal nostre grat la posseexen. On, segons assò, Sènyer, es significat als sants religioses que vos los esperats cada dia, con ells fassen per amor de vos so que vos feés per amor dells: e poden ésser certs e segurs que si ells se giten a martire per amor de vos, que vos los exoirets de tot so que ells volrán complir en est mon per donar laor de vos" (Llibre de contemplació en Déu, 1273-74; c. 112, §10-12; ORL IV: 58-59); "En diversitat de sextes e de crehenses són engenrrades guerres e batalles e·s repremuda la sancta sgleya en fe, caritat, sperança. Cor la manera, per la qual ach començament e exelçament e perfecció la sgleya Romana, s'és quax girada en guerres e en batalles e és quaix oblidada la primera manera, so és de prehicament e de convertiment e endressament, com los infaels sien endressats a vi[d]a perdurable, en la qual benahurança no ha fi. Batalles e guerres molt [mils] se convenien en lo poble dels jueus contra los infaels, ans que fos l'eveniment del Fill de Déu, que no fan ara en lo poble dels christians. E açò és per ço cor Jhesuchrist en sa passió ha molt encarreguats per caritat, devoció e eximpli los seus homes com per amor d'eyll no sien duptades engoxes, penes ni greu mort. E passiència és demostrada d'obra e per açò per esperiència membrada, entesa e amada en la sancta vida dels apòstols e dels martis, qui convertiren lo món ab batalles de passiència, caritat, humilitat, devoció, sperança, fortitudo, turmens e mort, [pot] ésser conegut qual manera se cové a examplar e créxer e sostenir la fe cathólica, ab lo qual exemplament e sosteniment se cové son começament, son mitj à e sa fi. Per speriència de les guerres e de les batalles, que·ls reys christians, prínceps e grans barons, cavallers e altres hörnens, han fetes contra·ls sarrayns, pot hom conèxer e saber que per altre manera pus alta e pus noble és possíbol cosa a convertir lo món e a conquerre la sancta terra d'Oltramar, que no és ceylla que·ls christians han presa contra·ls infaels per guerres e per batalles sensuals contra les intel·lectuals batalles, la qual manera és semblant a la primera segons que los sarraÿns han començada e muntiplicada lur secta. E açò matex se segueix dels tartres e dels infaels, qui per armes de fust e de ferre alcien los hòmens, sens que no·ls endreçen ni·ls vençen ab armes de fe, sperança, caritat, justicia, prudència, fortitudo, temprança, veritat e passiència" (Llibre contra Anticrist, 1274-76; cap. 'De guerres e de batalles'; ed. Perarnau, 1990: 154-156); y "Parlà Entenció e recontà que la galifa de Baldac qui era sarraí, escriví a l'apostoli unes letres en les quals deya que la secta dels sarrains era multiplicada per espasa e per força darmes; per que ell se maravellava molt de lapostoli e dels reys cristians, car ells volien e cuydaven la fè romana multiplicar per armes de fust e de ferre, e car no son armes ab les quals sia començada la fè catòlica la qual començà $a b$ armes de fè e ab preycació e ab martiri, segons que es recontat en la vida dels apòstols. On, per açò los fa a saber que ja dentrò que sien los cristians retornats a la intenció que esser solíen en examplar e honrar la fè, ja no hauràn poder que examplar la puxen, car defallen de entenció; per que la fè nos pot araygar en entenció estranya e qui no sia de sa natura ni de sos començaments" (Llibre de Santa Maria, 1290-92; c. 20, § 10; ORL X: 154-155; historia referida en obras anteriores: Ars notatoria, 1274-76; ed. Gayà Estelrich 1978: 35s; Romanç d'Evast e Blaquerna, 1276-83; c. 80, §1; ORL IX: 295-296, y Llibre de meravelles, 1287-89; Obras III.1: 79-80).

20 Por ejemplo, así se dirige a Bonifacio VIII y a los cardenales: "Supplicamus ut ipsi dictam viam amplectantur, cum inter omnes vias ad convertendum infideles et recuperationem Terrae Sanctae, ista sit levior, facilior, velocior et amicabilior et magis consona Charitati. Et tanto fortior quam omnes aliae viae quanto fortiora sunt arma spiritualia quam corporalia. Haec enim armatos suos non onerant nec molestant, non hebetantur ictibus, non franguntur, non rubiginantur algoribus, nec dissolvuntur caloribus, sed quanto plus in virtute eorum agitur tanto subtilius acuuntur et multiplicius multiplicantur; et armatos suos agiliores, fortiores, armatiores et audaciores faciunt plus in medio et in fine quam in principio. Praeter multa alia quae omittimus enarrare, ne videamur saecularibus potestatibus videamur in aliquo derogare. Licet ipsi 
ban llevando a cabo las cruzadas ${ }^{21}$. No obstante, pese a situar en un lugar superior a la misión intelectual y espiritual, Llull sugirió en ocasiones la conveniencia de combinar la acción misionera y el uso de las armas corporales ${ }^{22} \mathrm{y}$, a partir de la caída de Acre en 1291, escribió importantes tratados y epístolas a los dirigentes religiosos y políticos de la cristiandad en los que exponía minuciosamente cómo habría de organizarse una cruzada militar — siempre subordinada, eso sí, a la misión intelectual y espiritual—²3.

La pregunta fundamental que motiva este trabajo - y que espera ser respondida en uno ulterior - es cómo se conjugan y relacionan en el pensamiento luliano la misión mediante armas intelectuales y espirituales y la cruzada mediante armas sensuales o corporales. A pesar de que ha sido ampliamente tratado, considero que el tema no está zanjado y que aún existen posibilidades de estudiarlo superando viejos esquemas interpretativos. A continuación revisamos y discutimos las distintas propuestas historiográficas existentes, a fin de establecer las bases de un estudio futuro encaminado a aclarar la relación entre ambos conceptos - en definitiva, la problemática del uso de la violencia en nombre de la fe en la tarea evangelizadora - en el pensamiento de Ramon Llull.

Atrás debe quedar la imagen presentista de un Llull pacifista radical y promotor del diálogo intercultural e interreligioso, pues, si bien es cierto que fue crítico con las cruzadas, también lo es que escribió obras en que las promovía con todo detalle. ¿Cómo entender esta aparente contradicción? ¿Fue, como se ha dicho, un autor contradictorio, inconstante e inconsistente que cambió radicalmente de opinión, evolucionando desde una ingenuidad inicial que condenaba la acción militar hasta un ulterior realismo que la exigía? ¿Hemos de renunciar a considerar el pensamiento luliano como un todo coherente y profundamente unitario? ¿Qué es lo que Llull criticó exactamente de las cruzadas?

Creo que la investigación puede tomar nuevos rumbos alejados tanto de los excesos de la visión buenista - la del Llull anticruzadista y pacifista a ultranza-, como de los del

possint et debeant rationabiliter dicere et cogitare quod arma clericorum sunt nobiliora et fortiora quam arma eorum" (Liber Apostrophe seu De articulis fidei, 1296; MOG IV: ix, 57 [561]).

${ }_{21}$ Algunos de los pasajes más conocidos en los que Llull condena la manera en que se estaban llevando a cabo las cruzadas se encuentran en: Llibre de contemplació en Déu (1273-74; c. 112 [ORL, IV: 57-63]; c. 204 [ORL, V: 310-318]; c. 284, § 24; c. 287, § 17 y c. 309, § 22 y § 24 [ORL, VII: 150, 178 y 419-420]); Ars notatoria (1274-76; ed. Gayà Estelrich, 1978: 35s); Llibre contra Anticrist (1274-76; ed. Perarnau, 1990: 154ss); Romanç d'Evast e Blaquerna (1276-83; c. 80, § 1; ORL, IX: 295-296); Llibre de meravelles (1287-89; Obras, III.1: 79-80) y Llibre de Santa Maria (1290-92; c. 20, § 10; ORL, X: 154s).

22 Al respecto es importante señalar que ya en obras anteriores a la caída de Acre Llull sugiere la posibilidad de combinar la predicación y el uso de las armas. Véase, por ejemplo el Llibre de contemplació (c. $358, \S 29$ y $360, \S 9$; ORL VIII: 530-531 y 547-548); el Blaquerna (c. $80, \S 11 ; 81, \S 3-6$; 82 y 87, § 5; ORL IX: 301-302; 304-306; 310-315 y 339) o el Liber Tartari et Christiani seu Liber super Psalmum 'Quicumque vult' (1288; MOG IV: v, 30 [376]).

${ }_{23}$ Los tratados de cruzada son el Liber de passagio [Tractatus de modo convertendi infideles y Quomodo Terra Sancta recuperari potest] de 1292 (ROL XXVIII: 323-353); la Petició de Ramon al papa Celestí V per a la conversió dels infidels de 1294 (ed. Perarnau i Espelt 1982); la Petitio Raimundi pro conversione infidelium ad Bonifatium VIII papam de 1295 (ROL XXXV: 405-437); el Liber de fine de 1305 (ROL IX: 233-291); el Liber de acquisitione Terrae sanctae de 1309 (ed. Longpré 1927 y ROL XXXVIII: 157-229); el Liber natalis pueri parvuli Christi Jesu de 1311 (ROL VII: 19-73) y la Petitio in concilio generali de 1311 (ed. Longpré 1935 y Wieruszowski 1935: 420-5). 
sector que niega la unidad y coherencia de su pensamiento o que lo toma como ejemplo del proselitismo y el fanatismo al que - les gustaría poder decir- está abocado todo creyente convencido de la verdad de su fe. Para ello habrá que formular a los textos nuevas preguntas —o reformular viejas preguntas desde nuevos enfoques- $\mathrm{y}$, sobre todo, devolver la cuestión de la misión y la cruzada a su lugar originario: el conjunto del pensamiento y obra de Llull (no podrá, por tanto, ser analizada como una parte aislada de su pensamiento, sino como plenamente integrada dentro del mismo) en el contexto histórico-cultural de la cristiandad a caballo entre los siglos XIII y XIV (habrá que evitar, por tanto, miradas presentistas de todo tipo).

\section{Perspectivas historiográficas}

\subsection{El Ramon Llull misionero y pacifista}

Desde el siglo XIX y durante el primer tercio del XX numerosos autores estudiaron a Ramon Llull como misionero y como teórico de las misiones, viendo en él un precedente de la misionología contemporánea y calificándolo como el más grande y primer misionero a los mahometanos $^{24}$. Construyeron una imagen idealizada del Llull misionero en tierras islámicas con la que, me atrevería a decir, muchos de ellos soñaban, como sugiere Zwemer al afirmar que las obras del mallorquín contienen "glorious watchwords for the spiritual crusade against Islam in the twentieth century"25. En base a una lectura parcial y no debidamente contextualizada de algunos de los escritos del mallorquín — pasando por alto aquellos en los que propone combinar las armas espirituales y las armas materiales - , Llull fue presentado durante décadas como una suerte de activista pacifista medieval, defensor del ecumenismo, promotor del diálogo interreligioso e intercultural y crítico del uso de la violencia en nombre de la religión: una imagen apetecible para la mentalidad actual, pero que no es sino un espejismo que resulta de mirar el pasado desde parámetros eminentemente presentistas ${ }^{26}$.

Aunque en ocasiones la figura de Llull siga apareciendo idealizada según valores y parámetros actuales - llegando, por ejemplo, a ser presentado como una "primera ONG

\footnotetext{
24 Vid. Civezza, Storia universale..., pp. 575-599; Zwemer, Raymund Lull. First Missionary to the Moslems; BARBer, Raymond Lull, the illuminated doctor...; Richter, "Raymund Lullus. Ein Pionier..."; GoYAu, Figurines franciscaines, pp. 63-71; VAlls, "L'ideale missionario...”; Altaner, "Glaubenszwang...."; Frediani, "Profili di Missionari..."; Mietta, "Un grande missionario..." y Palma, "El gran misionero medioeval".

25 Zwemer, Raymund Lull. First Missionary to the Moslems, p. 148.

26 En esta línea del radical pacifismo luliano, Puigdollers, "Doctrinas pacifistas..."; Alòs Moner, "Idees lul-lianes..."; PALma, "La doctrina jurídica...", "Ramon Llull, pacificador" y "El procurador de infieles"; Caldentey Vidal, "La paz y el arbitraje..." y Urmeneta, "El pacifismo...". Llull llegó a ser visto como precursor de la Sociedad de las Naciones (VAlls i Taberner, "La Societat..." y Palma, "Ramón Lull y la Sociedad..."), como "uno de los primeros paladines del internacionalismo pacifista" (URMENETA, "El pacifismo luliano", p. 199) y como un "representante del espíritu popular, democrático, universalista y libre de Cataluña" (Elías de Tejada, Las doctrinas..., p. 100).
} 
unipersonal" ${ }_{27}$ _ , por lo general los mayores conocedores de su pensamiento han superado aquella visión de un pacifismo a ultranza entendido a la manera contemporánea. La actitud ciertamente pacifista de Llull no consistía en una oposición frontal al uso de armas en la vida política — pues, como veremos a continuación, entendía que en determinadas circunstancias el recurso a la fuerza podía ser legítimo-, y más bien ha de ser entendida como una "aspiración moral" 28 o "como el fin a que debe estar orientada la vida social y la política, tanto interior como exterior" 29 ; en suma, como el ideal hacia el que una sociedad cristiana, movida por el principio de caridad, debería tender ${ }^{30}$. Y es que, si bien es verdad que encontramos a lo largo de toda su obra numerosos pasajes en los que condena severamente el uso de las armas y en los que sostiene que la conversio infidelium y la recuperatione Terrae Sanctae han de realizarse siguiendo el método de los apóstoles, que la conquistaron mediante la predicación, el amor, las oraciones y derramando su propia sangre, es igualmente cierto que en otras ocasiones Ramon combina la predicación y el uso de las armas y que escribió importantes tratados en los que expuso minuciosamente cómo habría de organizarse una cruzada militar. ¿Cómo explicar esta aparente contradicción?

\section{2. ¿Misión o cruzada? Primeros intentos de respuesta: la cruzada al servicio de la misión}

El primer modelo de respuesta - que encontramos en Carreras i Artau, Sugranyes de Franch, Llinarès, Hillgarth o Garcías $\mathrm{Palou}^{31}$ - es aquel que trata de salvaguardar la coherencia del pensamiento de Llull argumentando que, si bien hay una evolución en sus ideas que le lleva a integrar la cruzada armada dentro de sus planes misioneros, ésta ocupa siempre un lugar secundario, instrumental y subordinado a la misión intelectual y espiritual destinada a la conversión de los infieles. Cruzada, misión y conversión, además, se integran dentro de planes más amplios de reforma social, política, moral y religiosa de la cristiandad, de modo que la conversión de los infieles no es sino otra etapa, indispensable, del regreso de todos los pueblos a la unidad de la Ciudad de Dios.

\footnotetext{
27 Pallejà de Bustinza, "Ramon Llull....".

8 Carreras i Artau, Historia de la Filosofía..., p. 627.

9 BAUZÁ Y BAUZÁ, "Doctrinas jurídicas internacionales...”, p. 39.

30 En este sentido, siempre que contextualicemos debidamente las ideas de Llull y evitemos caer en cuestionables presentismos (Llull como "precursor de la Sociedad de las Naciones", como "representante del espíritu popular, democrático, universalista y libre de Cataluña" o como "primera ONG unipersonal"; cfr. notas 25-26), es perfectamente legítimo subrayar el valor o el mensaje que el pensamiento de Llull puede tener para el mundo actual, tal y como hacen JAULENT, "Mudança nos valores e a paz mundial...", Walter, "C'è un messaggio di Raimondo Lullo...?” o CAlPe Melendres, "La relación intelecto-voluntad en el método misionológico luliano...”. Agradezco al corrector que me animase a revisar y reflexionar sobre lo dicho en este párrafo.

31 Carreras i Artau, Historia de la Filosofía..., pp. 265-266, 335-338 y 621-634; SugranYes De Franch, "Un texte...", Raymond Lulle..., "Els projectes..." y "La doctrina misional...", "Ramon Llull i l'Islam", "L'apologétique...”, "Les propostes...” y "La obra misional..."; Llinarès, Raymond Lulle...; HiLlGarth, Ramon Llull an Lullism..., "La vida i la significació..." y "Vida i importancia de Ramon Llull...", y Garcías PALOU, Ramón Llull y el islam.
} 
Estos autores coinciden en afirmar que la evolución que constatamos a partir de 1291 (año de la caída de San Juan de Acre y en torno al cual escribió las primeras obras de cruzada) o 1293 (cuando viajó a Túnez y entró en contacto con un islam no sometido a poderes cristianos ${ }^{32}$ ) no es un cambio radical de actitud, sino tan solo "una cuestión de acento" ${ }^{33}$, pues sus tesis fundamentales fueron siempre las mismas: ya en obras anteriores Llull había sugerido la combinación de las armas intelectuales y espirituales y las armas sensuales, pero éstas siempre aparecen subordinadas y en menor calidad que las anteriores ${ }^{34} \mathrm{y}$, en fin, Llull fue siempre crítico con la cruzada, incluso en aquellas obras que tenían por objeto proponer un nuevo passagium ${ }^{35}$. Así, contrastar como polos opuestos el primer énfasis misionero que vemos en sus obras más tempranas con los últimos planes de passagio es equivocado, porque, aunque no hubiese escrito tratados específicos de cruzada hasta 1291, ya la había considerado necesaria mucho antes, eso sí, siempre como un instrumento subordinado a la misión con el único objetivo de posibilitar la predicación misionera en tierras musulmanas, nunca de imponer la conversión. Este dato es importante, porque significa que la caída de Acre en 1291 no supuso un cambio de fondo en el pensamiento de Llull acerca de la cruzada, sino tan solo un nuevo contexto sociopolítico en el que poder hacer escuchar sus propuestas misioneras.

De este modo, tampoco habría un cambio de actitud o de pensamiento - un apparent volte-face, como han visto algunos ${ }^{36}$ - en la propuesta del prólogo del Liber de participatione (1312) $)^{37}$, cuando tras veinte años escribiendo tratados de conversión y cruzada, Llull parece regresar a la defensa exclusiva de la predicación intelectual y pacífica y al

\footnotetext{
32 Llinarés (Raymond Lulle...) aboga por situar el punto de inflexión en esos primeros contactos con el islam no sometido, a partir del cual cambió el tono apologético de Llull. Así, Llinarés distingue dos momentos en la teoría luliana del 'combate por Dios': 'los tiempos del diálogo', en los que Llull adopta una postura respetuosa, pacífica y dialogante como la que muestran los tres sabios, judío, cristiano y musulmán, del Llibre del gentil e dels tres savis, y 'los tiempos de las disputas', en los que abandona la postura dialogante y muestra una actitud más hostil hacia sus interlocutores, como vemos en la Disputació dels cinc savis (1294) o en la Disputatio Raimundi christiani et Homeri saraceni (1308).

33 Sugranyes de Franch, "Els projectes de creuada...”, p. 289. Atrás quedaba la explicación psicológica según la cual Llull, desanimado por el poco éxito de sus campañas en favor de las misiones, terminó cediendo a la presión de su entorno y a los intereses de la política de los papas y príncipes europeos (Altaner, "Glaubenszwang....").

34 Carreras i Artau, Historia de la Filosofía..., pp. 625ss.; GoÑ Gatzambide, Historia de la bula..., pp. 250ss; Hillgarth, Ramon Llull an Lullism..., p. 51 y "Vida i importancia...", p. 974. Véase la nota 21. A la luz de estos datos, Garcías Palou habla no de dos sino de tres momentos en el pensamiento luliano: una primera etapa (hasta 1283/5) 'pacifista' en la que propone exclusivamente la predicación y el diálogo; una segunda etapa (1283/5-1292) en la que comienza a insinuar la posibilidad de vincular la conquista bélica a la cruzada espiritual, aunque con interés prioritario en la misión, y una tercera etapa (desde 1291/2) en la que ambos ideales aparecen perfectamente compatibilizados en toda una serie de tratados en los que se especifica cómo ha de organizarse el passagium, no siendo éste un fin último, sino un medio para posibilitar la misión y la predicación (Garcías Palou, Ramón Llull y el islam, pp. 419-438).

35 Passagium (passatge en romance) era uno de los términos utilizados en el siglo XIII para referirse a lo que la historiografía ha denominado cruzada.

36 Así lo interpretan, entre otros, Gotтron, "Ramon Lulls Kreuzzugsideen", p. 49; Altaner, "Raymundus Lullus..." y DANIEL, Islam and the West..., p. 180.

37 El texto del Liber de participatione, en ROL XVI: 246.
} 
rechazo de la cruzada: el mallorquín no había abandonado jamás su preferencia por las armas intelectuales y espirituales y, si ésta aflora de nuevo y con nitidez en este momento, ello se debe a una nueva situación — su acercamiento a Federico III y el contexto político-religios tunecino, más favorable - en la que la cruzada armada no resultaba ni probable ni necesaria. En definitiva, la clara preferencia por la misión intelectual y espiritual, ideal siempre presente en sus obras, incluso en aquellas destinadas a promover una campaña ad acquirendam Terram Sanctam, lleva a estos autores a sostener que Llull nunca fue inconsecuente o incoherente con sus ideas ${ }^{38}$.

\subsection{Más allá de la subordinación de la cruzada a la misión: algunas voces críticas}

Aunque estos estudiosos tenían razón en lo esencial — la consideración de un Ramon Llull que, lejos de ser contradictorio, estuvo siempre convencido de que el mejor método para la propagación de la fe cristiana era la misión mediante el testimonio espiritual y, sobre todo, la predicación racional-, algunas de sus conclusiones y afirmaciones acerca de la tolerancia y el anticruzadismo lulianos fueron contestadas en los años ochenta y noventa por diferentes autores que se esforzaron por subrayar las contradicciones que ellos veían en el pensamiento del mallorquín.

Dominique Urvoy, aunque veía en Llull una buena voluntad hacia los musulmanes muy diferente al clima de sospecha que rodeaba a ciertos sectores de la sociedad mallorquina, argumentó que estas contradicciones se debían a que los musulmanes con los que había mantenido contactos reales, siempre bajo la dominación cristiana, no eran de la misma categoría que aquellos intelectuales y hombres de religión a los que pretendía convertir racionalmente: su método estaba abocado al fracaso porque los musulmanes no le podían entender ${ }^{39}$. Algunos años después, Miquel Barceló daría un paso más al caracterizar el proyecto misionero de Llull como un anticipo del espíritu colonial europeo y como una suerte de orientalismo tal y como lo definió E. W. Said: Llull, en el fondo, solo sabía predicar a audiencias cautivas y se vio obligado una y otra vez — por la propia esterilidad de su método misionero- a buscar "«su" islam [...], el entrañable islam de los esclavos domésticos", elaborando una "teología de la colonización" en la que se imponía la "racionalidad de la fuerza", en oposición a la fuerza de la racionali$\mathrm{dad}^{40}$. No obstante, la postura del autor queda retratada cuando manifiesta su voluntad de no volver a asistir a sesiones dedicadas a perseguir las "huidizas especulaciones de

\footnotetext{
38 Hillgarth afirma que "Llull no és inconsequent a un nivell mes profund" (Hillgarth, "Vida i importancia”, p. 974).

39 Unvoy, Penser l'Islam y "Les musulmans pouvaient-ils comprendre l'argumentation lullienne?".

40 BARCELó, “«Per sarraïns a preïcar»...”, p. 129. En términos similares a los de Said, dice que "Llull pensa «l'altre» — contra el qual fingeix que polemitza — sense que aquest mai no pugui, almenys inicialment, evitar ser pensat" (ibíd., p. 128).
} 
clérigos fanáticos y obcecados", añadiendo que los términos adecuados para referirse a los proyectos de Llull son "exterminio, predicadores armados, audiencias cautivas..." Benjamin Z. Kedar, por su parte, se empeñó en mostrar a un Llull de "many opinions", definiéndolo como "a man who ran almost the entire gamut of positions" ${ }_{42}$, para terminar presentando a un Llull contradictorio que, en el fondo, nunca habría rechazado el recurso a las armas y que, al contrario, tuvo siempre presente la idea de cruzada, tanto en la época anterior a 1292 como en los años posteriores a 1311, en los que otros autores habían visto un retorno a posiciones anticruzadistas. En este sentido, Kedar ve en el Liber de civitate mundi, último libro escrito en 1314 antes de partir hacia Túnez, una clara y definitiva afirmación a favor de la cruzada que demuestra que Llull jamás renunció a ella, solo que, al ver que nadie le apoyaba, decidió hacer la única cosa que podía hacer él solo: volver a tierra de sarracenos para predicar según su $\operatorname{Ars}^{43}$. Otro aspecto que aborda Kedar, igual que Barceló, para desmantelar aquella visión defendida por Carreras i Artau, Sugranyes de Franch y el resto, es el de la 'evangelización obligatoria' o 'catequización forzada' a judíos y musulmanes en territorio cristiano, práctica que, en su parecer, evidenciaba una actitud intransigente, partidaria del uso de la fuerza y en ningún caso tolerante ${ }^{44}$.

Por otro lado, Colomer i Pous, convencido de que se ha subrayado hasta el exceso el tono sereno, abierto y cordial de las obras de controversia religiosa de Llull y de que ciertas visiones generalizadoras parecen no dar importancia a la evolución de las mismas, retoma la distinción de Llinarès entre los 'tiempos del diálogo' y los 'tiempos de las disputas' y la completa diferenciando no dos sino tres etapas: el diálogo abierto

\footnotetext{
41 "Mai més no tornaré, doncs, a assistir a sessions dedicades a perseguir besllums i reflexos, fugisseres especulacions de clergues fanatics i obcecats. Els mots justos són extermini, predicadors armats, audiències captives...” (BARCELó, “«Per sarraïns a preïcar»...”, p. 130).

42 Kedar, Crusade and Mission..., pp. 189-199. Es interesante la relación que establece entre la idea luliana de subordinación de la cruzada a la misión con los planteamientos de Inocencio IV: aunque los musulmanes no debían ser coaccionados para aceptar la fe cristiana, el papa sí podría recurrir al brazo secular para obligarles a aceptar misioneros, de modo que, si la conversión forzada era inadmisible, la guerra destinada a abrir camino a los misioneros era legítima si era autorizada por el papa.

43 En el fragmento (ROL II: 194-199, esp. 197), el personaje Justicia declara que es un deber del Imperio defender a la Iglesia con la espada frente a los cismáticos, los cristianos injustos y los infieles que retienen la Tierra Santa. Pero al final no se impone esa visión 'justiciera', sino que el resto de Dignidades divinas imponen una solución diferente que tiene en cuenta también a Misericordia, Gracia, Humildad y Piedad. Vid. Kedar, Crusade and Mission..., pp. 198-199.

44 Opinan diferente Eusebi Colomer i Pous, Mark D. Johnston o Josep Perarnau i Espelt. Colomer i Pous considera que se trata solo de un "uso de la época" ante el que Llull no experimentó "la repugnancia que siente el hombre moderno", sino que, viendo en él un instrumento ventajoso para la misión, acabó abrazándolo e introduciendo la fuerza al servicio de sus proyectos misioneros, y que de ninguna manera constituye un atentado contra la 'libertad religiosa', ya que los infieles eran obligados a asistir a los sermones y catequesis y a aprender la doctrina cristiana, pero en ningún caso a creer o a bautizarse (Colomer i Pous, "Ramón Llull y el judaísmo...”, pp. 39-44.). De forma similar, tras un estudio exhaustivo de las propuestas lulianas al respecto, Johnston concluye que un análisis adecuado de la cuestión socava cualquier argumento que sostenga que la actitud de Llull manifiesta "la «intransigencia religiosa» de un celoso proselitista" (Johnston, "Ramon Llull and the Compulsory Evangelization...", pp. 36-37). En una línea similar, véase la argumentación de Perarnau i Espelt en el apartado siguiente.
} 
de la primera época se convierte poco a poco en controversia apologética para acabar finalmente en polémica ${ }^{45}$. Asimismo, relativiza el concepto de diálogo y sostiene que el cambio de actitud de Llull en sus obras de controversia se debe a una contradicción entre teoría y praxis (o entre monólogo y diálogo): sus 'diálogos' eran, al principio del todo, monólogos en los que el autor hablaba a través de sus propias criaturas fingidas, sabios idealmente imaginados; en Túnez y Bugía, en cambio, Llull se encuentra por primera vez frente a un interlocutor real, vivo y autónomo que razonaba por sí mismo, de modo que fracasa el 'diálogo' y se abre paso la disputa real. Por último, en lo relativo a la misión y la cruzada, identifica una evolución desde un 'idealismo quijotesco' hacia un pragmatismo y realismo mayores, aunque Ramon nunca abandonó del todo la utopía y siempre mantuvo como ideal prioritario la conversión de los infieles por medio de la predicación y la misión.

Este grupo de autores hizo hincapié en los elementos de cambio y evolución del pensamiento de Lull, alejándose de la imagen mantenida hasta entonces - que ciertamente en algunos puntos resultaba un tanto edulcorada o idealizada - y llegando a la conclusión de que el pensamiento del mallorquín fue cambiante (Colomer i Pous), cuando no inconsistente y contradictorio (Kedar). Así visto, Llull era un oportunista político que cedió a las presiones y mentalidad de su tiempo, evolucionando desde un idealismo utópico inicial hacia un ulterior realismo pragmático (Urvoy, Colomer i Pous), y, en el fondo, jamás se había opuesto al uso de la fuerza y a la cruzada (Kedar, Barceló).

Hasta aquí, la cuestión había sido abordada desde un análisis textual descriptivo y comparativo, exponiendo, primero, los pasajes en los que Llull abogaba por una cruzada espiritual e intelectual y condenaba categóricamente la fuerza corporal; después, aquellos en los que combinaba la vía de la predicación con la vía de las armas, y, por último, los detallados planes de passagium. Sus ideas y proposiciones fueron debidamente contextualizadas en la realidad política de su tiempo, pero, aun así, el historiador que pretendía entender a Llull se topaba con tantas opiniones contradictorias que no podía sino adherirse, perplejo, a la tesis defendida por Kedar de que Llull fue inconsistente o incongruente, o bien seguir admitiendo la teoría de Sugranyes de Franch, Hillgarth

\footnotetext{
45 Colomer i Pous, "Ramón Llull y el judaísmo...", "Ramón Llull y el judaísmo...(2)", "Ramón Llull y su actitud...”, "El pensament ecumènic...”, "El pensament de Ramon Llull...”, "Ramón Llull y Ramón Martí”, "La actitud compleja y ambivalente...", "El Diàleg interreligiós...” y "L'encontre de les religions...”. De la primera época son paradigmáticos el Llibre del gentil (1274-76), el Liber de Sancto Spiritu (1274-83) y el De adventu Messiae (1274-83), los tres con final abierto. En la segunda fase encontramos el Liber Tartari et Christiani (1288) y la Disputació de cinc savis (1294), que no son estrictamente ni diálogo ni disputa, sino que, "bajo la forma de un diálogo que va convirtiéndose en monólogo, ambas obras [...] son ya una decidida apología del cristianismo" (Colomer i Pous, "La actitud compleja y ambivalente...", p. 79). El punto final de esta evolución lo representa la Disputatio Raimundi christiani et Homeri saraceni (1308) en la que se hace palpable la auténtica dureza del ambiente religioso medieval.
} 
y tantos otros de que, en el fondo, no hay contradicción en Llull sencillamente porque siempre situó la misión por encima de la cruzada armada. Ambas posturas tienen parte de verdad, pero no terminan de abrazar o de comprender la complejidad del pensamiento luliano sobre el problema del infiel.

\section{4. 'Ad bonum statum reducere uniuersum et ad unum ouile catholicum adunire': una comprensión global del pensamiento luliano}

Desde mediados de los años noventa, un nuevo grupo de autores intentó superar la polarización del debate entre las dos posiciones apenas descritas. Pamela D. Beattie ${ }^{46}$ abandonó la contraposición entre los conceptos de cruzada y misión: éstas no son realidades contrarias sino complementarias, expresiones diferentes de una misma religiosidad, y la oposición entre misión y cruzada pertenece a la historiografía más que a la realidad medieval ${ }^{47}$. Beattie, por otro lado, estaba firmemente convencida de que es imposible entender de verdad las ideas de Llull acerca de la misión y la cruzada si éstas no son contempladas holísticamente en el contexto total de su pensamiento teológico y antropológico, pues solo cobran sentido completo a la luz de su visión de la sociedad cristiana, de su concepción de la finalidad del ser humano y de su esquema de salvación, principios sobre los que el mallorquín construye sus propuestas misioneras y cruzadísticas y que han de ser rastreados no tanto en los tratados específicos de conversione infidelium y de recuperatione Terrae Sanctae, cuanto en el resto de su obra. En efecto, una lectura global de su pensamiento permite situar sus ideas de misión y cruzada en un lugar más adecuado: la cruzada, la dilatatio christianitatis, la misión y la conversión de los infieles, lejos de constituir un fin en sí mismas, son instrumentos para "ad bonum statum reducere uniuersum et ad unum ouile catholicum adunire" de forma que la humanidad pudiera realizar la finalidad última para la cual fue creada (entender, amar, recordar, honrar, servir y bendecir a Dios). En el fondo, en ese plan de reducere (devolver, reeducar, reconducir o llevar) el universo ad bonum statum, juegan un papel igual de importante la conversión de los infieles (misión ad extra), la unidad de los cristianos (retorno de herejes y cismáticos al 'ovil católico único') y la renovatio

\footnotetext{
46 Su tesis doctoral (BEATTIE, Evangelization, reform and eschatology...) fue, en mi parecer, pionera en esta nueva línea interpretativa. Vid. también BEATTIE, “"Pro exaltatione sanctae fidei catholicae...»”, "Eschatology and Llull's...", "Crusading and the Penitential Life..." y, sobre todo, "Ramon Llull's Crusade Treatises".

47 Entre quienes consideraban que cruzada y misión eran realidades opuestas, vid. Runciman, "The Decline of Crusading Idea"; Purcell, Papal crusading policy 1244-1291; Rousset, "La croisade obstacle à la misión" y KedAr, Crusade and Mission.... Beattie, en cambio, opina que eran actividades complementarias, expresiones diferentes de una devoción y piedad religiosa comunes (BEATTIE, Evangelization, reform and eschatology..., pp. 14ss; como ella también Siberry, "Missionaries and Crusaders..." y Criticism of Crusading 1095-1274; Housley, The Avignon Papacy...; Schein, Fideles Crucis...; CARdini, Studi sulla storia..., p. 118 y "Raimondo Lullo e la crociata...", p. 8; MAIER, Preaching the Crusades..., p. 161 y Domínguez Reboiras, "La idea de cruzada...", pp. 50-52.

48 Liber de fine (ROL IX: 251). Nótese la inspiración evangélica de la expresión: "et alias oves habeo quae non sunt ex hoc ovili et illas oportet me adducere et vocem meam audient et fiet unum ovile unus pastor" (Ioh 10,16).
} 
mundi o reforma moral de la cristiandad (misión ad intra — la corrupción moral de la sociedad cristiana, atrapada en intereses terrenales, fue una preocupación constante del mallorquín y era, según él, la causa de que la evangelización no funcionase-). Solo dentro de esta concepción unitaria y holística del pensamiento de Llull podemos comprender de forma adecuada sus ideas acerca de misión y cruzada, y es que, aunque pueda resultarnos paradójico o contradictorio, para él ambas iniciativas eran meritorias de acuerdo al lugar que ocupaban dentro de su concepción global de la finalidad del hombre. En definitiva, la misión intelectual y espiritual segons la manera dels apòstols y la cruzada armada son dos instrumentos - jerárquicamente ordenados: la cruzada está subordinada a las necesidades de la misión, siempre preferible - de los que disponen los cristianos para lograr la conversión de los infieles, meta que, más que un fin en sí misma, constituye, junto a la reforma moral de la cristiandad, un objetivo intermedio o instrumental — secunda intentio o means goal - para reconducir el mundo ad bonum statum y que la humanidad en conjunto y cada ser humano en particular puedan verse plenamente realizados en el plan para ellos diseñado por Dios — finis último, prima intentio o end goal del hombre-.

De forma casi paralela, Trías Mercant retomó el estudio de la apologética luliana y la cuestión de su supuesta tolerancia. Propuso analizar la producción de Llull de forma global y unitaria en lugar de examinar escritos singulares, lo cual permitiría que ese corte radical entre las tentativas de diálogo de unas obras y la hostilidad perceptible en otras terminara difuminándose, pues los libros individuales darían paso a la consideración de actitudes globales y tendencias definidas. En este sentido, matizó la idea de que existe en la obra apologética del mallorquín una evolución y, frente a esas etapas tan rígidamente definidas por Llinarès (temps du dialogue y temps des disputes) o Colomer (diálogo abierto, controversia apologética y polémica), señaló que en el pensamiento y método apologéticos lulianos no hay rupturas (tampoco las admite Llull), sino una profunda continuidad y coherencia. Asimismo, distingue entre una "tolerancia de benevolencia", que es una "actitud sociológica de respeto y comprensión del otro", y una "tolerancia racional", que define como "el puente epistemológico que se tiende entre la utopía de la unidad interreligiosa y la diversa realidad ideológica asentada en la multiplicidad de creencias" ${ }^{49}$, adscribiendo a Llull al segundo tipo: no es que tuviera un espíritu tolerante y respetuoso con el otro religioso, sino que, mediante esta tolerancia racional pretendió abrir un camino de conocimiento y entendimiento mutuo para superar la diversidad y mantener viva la llama del sueño de la unidad religiosa universal —unidad, eso sí, bajo el signo cristiano-.

En esta misma línea hemos de situar los trabajos de importantes teólogos lulistas. Jordi Gayà i Esterlich entiende el pensamiento luliano como una "teología para la misión" ${ }^{50} \mathrm{y}$ considera que Llull tiene un interés "cordial" por los musulmanes que le permite adoptar y sugerir una postura que no siempre es combativa — "quia ipsi infideles sunt homines,

\footnotetext{
49 Trías Mercant, "Judíos y Cristianos...”, pp. 66-70. Véase también íd., Ramón Llull... y "Las claves...”.

50 GayÀ Estelrich, "Ramon Llull, il suo impegno missionario", "Introducción", Raimondo Lullo..., "Ramon Llull i l'Islam..." y "Una teologia de la historia...".
} 
sicut et nos, et sunt de nostra natura" ${ }_{51}$ _ y que hace que nunca pierda la esperanza de que algún día se darían las circunstancias propicias para aquel diálogo que imaginó al comienzo de su carrera en el Llibre del gentil. Según Gayà, el tratamiento del passagium y de la conquista de Tierra Santa parece estar condicionado por sus negociaciones con los centros de poder con vistas a la intensificación de la acción misionera y a la institución de lugares para la preparación de los misioneros. De este modo, considera que, si Llull trató la cruzada, ello es, en primer lugar, porque era una realidad candente en su tiempo que tenía que incorporar a sus planes misioneros si quería encontrar apoyos; en segundo lugar, porque afectaba de lleno a sus planes de misión (en lo relativo a las órdenes militares, no le eran indiferentes los pasos que se pudiesen dar hacia una orden unificada, renovada en su estilo de vida y más comprometida con la misión; tampoco le podían ser indiferentes las disposiciones sobre la financiación de la cruzada, pues él buscaba asegurar la financiación de colegios de lenguas apelando casi a las mismas fuentes de recursos, y tampoco podía dejar de interesarle la implicación de las iglesias orientales y de los tártaros en la cruzada, dos puntos a los que presta mucha atención en su programa misionero) y, por último, porque, a pesar de subrayar la superioridad de las armas intelectuales y espirituales, compartía con sus contemporáneos la convicción de que la cruzada era una guerra justa y lícita — en contra de las voces que clamaban por un Llull radicalmente pacifista-.

Fernando Domínguez Reboiras ${ }^{52}$, por su parte, sostiene que la cuestión de la cruzada en Llull es mucho más compleja que una simple evolución desde un idealismo ingenuo y un pacifismo a ultranza iniciales hasta un pragmatismo más realista y una admisión de la fuerza corporal. En primer lugar, subraya que la contraposición radical de cruzada y misión es inaceptable, anacrónica y estéril y que constituye un error de método. En segundo lugar, considera que todas las propuestas de Llull —en contra de lo que opinaba Kedar - en realidad no sólo no se contradicen, sino que son coherentes con la idea central de su invariable y monolítico pensamiento misionero: "la conversión sin coacciones de todos los infieles dictada por un acto libre de su voluntad que se ha de conseguir a través de la comprensión racional de la mayor verdad contenida en la fe cristiana que se alcanza gracias a su nuevo método" ${ }_{53}$. Por otro lado, sostiene que lo que obligó a Ramon a incluir el passagium — cuestión que nunca fue de su preferenciaen su discurso misionero fue la relevancia y extrema actualidad que precisamente éste cobró tras la caída de Acre en la curia papal, para cuya política el movimiento cruzado contenía elementos imprescindibles que la sola misión pacífica no les proporcionaba ${ }^{54}$. Si Llull fue, pese a todo, siempre crítico con las cruzadas, ello se debe a que era plenamente consciente del proceso de "desnaturalización del fenómeno cruzado" 55 que se

\footnotetext{
51 Ars ad faciendum et ad solvendum quaestiones (1294-95; MOG V: v, 2 [378]).

52 Domínguez Reboiras, "Ramon Llull y la cruzada...", "El papa Nicolás IV...", "La idea de cruzada...",

"Raimundo Lulio y la Cruzada...", "Dios, el mundo y el hombre..." y Ramon Llull. El mejor libro....

53 Domínguez Reboiras, “La idea de cruzada...," p. 50.

54 Opina igual ColombA, "Passagium generale...".

55 Sobre este proceso iniciado a finales del siglo XII e intensificado a lo largo del XIII, vid. AyALA Martínez, Las Cruzadas, pp. 217-263.
} 
estaba produciendo; de que el passagium ya no respondía a una sincera voluntad de convertir a los infieles ni de recuperar Tierra Santa y de que el negotium Terrae sanctae ya no redundaba en beneficio de la expansión del cristianismo, sino que se había convertido en un verdadero negocio al servicio de los intereses seculares del papado y de cada reino y en fuente de legitimación de particularismos estatales o 'nacionales' ${ }^{56}$. Por último, dice que tan necesario es contextualizar las ideas de Llull sobre misión y cruzada en estas coordenadas histórico-ideológicas, como integrarlas en una visión de conjunto de su pensamiento filosófico, teológico y antropológico, y es que considerar a Llull como un mero autor de tratados de cruzada y como un oportunista político es una visión extremadamente reductiva ${ }^{57}$.

También el teólogo e historiador Josep Perarnau i Espelt ${ }^{58}$ se sitúa en esta línea interpretativa. Subraya que el Liber de passagio (1292) apunta mucho más alto que a la simple recuperatio Terrae Sanctae: apunta al objetivo máximo de su pensamiento, que el mundo y la sociedad abandonen su mal estado para que la humanidad pueda ver cumplida la finalidad para la que fue creada $^{59}$, y que todos los elementos de lo passatge habían sido ya expuestos en el Llibre de contemplació, cuya importancia reivindica como la primera síntesis del pensamiento misionero luliano ${ }^{60}$. El Liber de passagio respondía a la sensación de amenaza creada en Roma tras la caída de Acre, cuando Nicolás IV invitó a la Iglesia a hacer una reflexión comunitaria sobre cuál era el mejor modo de corregir el 'estado de las cosas' y a sugerir posibles medidas beneficiosas para la cristiandad, siendo dos temas centrales la reconquista de Tierra Santa y la posibilidad de unificar las órdenes militares. Llull, al escribir el Liber de passagio, respondía a esta llamada pontificia y aprovechaba la circunstancia para presentar a la curia su programa misionero - expuesto ya en el Llibre de contemplació - adaptado al proyecto papal de cruzada ${ }^{61}$. La revitalización de la cruzada tras la caída de Acre era una inme-

56 Domínguez Reboiras, “La idea de cruzada...”, pp. 55ss.

57 Domínguez Reborras, “La idea de cruzada...”, p. 74. Recoge la opinión de Cardini, Minima mediaevalia, p. 357. Sobre la teología y antropología lulianas, vid. Domínguez Reborras, "El discurso luliano..." y "Dios, el mundo y el hombre..."; Pardo Pastor, "Ramon Llull y el ars conuertendi...", y Romano y Cruz Palma, "The Human Realm".

58 Véanse sus importantes trabajos de edición (Perarnau i Espelt, "Un text català...", "La Disputació de cinc savis...", "El Llibre contra Anticrist..." y "La còpia manuscrita...") y otros artículos en que aborda la cuestión de la misión y la cruzada en Llull (Perarnau i Espelt, "Consideracions sobre el tema de Missió i croada...", "Reseña de ROL XXVIII" y "Certeses, hipòtesis i preguntes...").

59 Perarnau i Espelt, "Reseña de ROL XXVIII”, p. 549.

60 Perarnau i Espelt, "Consideracions sobre el tema de Missió i croada...".

${ }_{61}$ De hecho, una primitiva versión del Tractatus de modo convertendi infideles habría sido preparada por Llull mucho antes de 1291, para presentarle a Honorio IV en 1287 sus ideas y planes de misión y conversión de los infieles. Esta primera redacción del Tractatus comenzaría con el que luego sería el capítulo III ('de modo convertendi'), de manera que los dos primeros ('de modo bellandi per terra' y 'per mare', cuyo contenido no se refleja en el título del Tractatus) habrían sido añadidos posteriormente cuando, una vez perdido Acre, Nicolás IV invitó a la cristiandad a reflexionar sobre el modo de recuperar Tierra Santa. Así, a principios de febrero de 1292 presentó al papa el Tractatus y, unos meses más tarde, el memorial Quomodo Terra Sancta recuperari potest, que completaba lo expuesto en el anterior partiendo, a diferencia de aquél, del presupuesto de la unificación de las órdenes militares. Este proyecto de recuperatione 
jorable ocasión para exponer al papa los dos puntos esenciales de su mensaje: llevar la Iglesia y el mundo ad bonum statum - es decir, reformar la cristiandad - y lograr la conversión de los infieles y cismáticos al cristianismo (ad unum ouile catholicum adunire) para que Dios fuese alabado, servido, conocido, recordado y amado por toda la humanidad. En definitiva, también Perarnau i Espelt rechazó la tesis que sostenía que la cruzada armada había sido siempre considerada por Llull como parte integrante necesaria de su propuesta para la conversión de los infieles, que se sintetizaba en un punto fundamental que el mallorquín mantuvo intacto en lo esencial desde el Llibre de contemplació hasta tratados como el Liber de passagio o el De fine: "la continuïtat de l'actuació evangelitzadora de Jesucrist i dels apòstols" ${ }^{2}$. La cruzada militar solo es lícita en caso de defensa contra un ataque como el de Acre y siempre está sometida a la misión, entendida como el medio más conveniente "ad exaltationem fidei Ecclesia" según el "modum Christi et apostolorum et martyrum"ø3.

Por otro lado, abordó la cuestión de la 'evangelización obligatoria' y demostró cómo las escuelas destinadas a los judíos y musulmanes que vivieran bajo jurisdicción cristiana no tenían como objetivo la conversión de sus alumnos como fruto de una catequesis obligada, sino únicamente clarificar, intelectual y gramaticalmente, el verdadero contenido del credo cristiano. Estas escuelas para sarraïns e jueus catius, al igual que los centros de intercambio de sabios como el propuesto en el Liber de participatione, tenían un fin muy claro que nada tenía que ver con la conversión o el adoctrinamiento de sus alumnos: mostrar y aclarar las creencias del alter religioso para acabar con los prejuicios que unos y otros se habían formado de la religión contraria y que imposibilitaban la discusión fructífera y establecer, por tanto, las bases reales de la confrontación religiosa. Pero ni los sarraceni bene litterati de los centros de intercambio ni los sarraïns e jueus catius habrían de convertirse al cristianismo: lo único que esperaba Llull es que en esos centros o escuelas recibiesen un conocimiento correcto de los artículos de la fe cristiana y los argumentos a su favor, de manera que, superada la formación en la escuela, "se'n vagen ab enteniment il·luminat e ab consciencia nafrada per la sciéncia que enfre los chrestians hauran apresa sobre la revelació de la fe cathólica" ${ }^{64}$. Así, mientras que otros autores habían visto en la 'evangelización obligatoria' una prueba fehaciente de que Llull habría considerado necesario el uso de la fuerza para lograr la conversión de los infieles desde el principio, Perarnau sostiene que la propuesta luliana de que "per força lur [a alcuns sarraïns qui són catius e alcuns jueus] faça mostrar la nostra creença en qual manera creu en lo subject e en lo predicat" ${ }^{\prime 65}$ no implicaba en ningún caso una idea

vislumbrado en el Quomodo, sería desarrollado, in extenso y de manera definitiva, en el Liber de fine. Con todo, el tema de la misión, la fundación de escuelas de lenguas, la predicación y la conversión de los infieles es siempre el tema prioritario. Vid. Perarnau i Espelt, "Reseña de ROL XXVIII", pp. 550-551 y "Certeses, hipòtesis i preguntes...", pp. 491ss.

${ }_{62}$ Perarnau i Espelt, "Certeses, hipòtesis i preguntes...,", pp. 485.

63 Tractatus de modo convertendi infideles, IV.2 (ROL XXVIII: 344).

64 Llibre contra Antichrist, ed. Perarnau i Espelt, 1990: 151-152.

65 En el citado pasaje (Llibre de contemplació en Déu, c. 346 § 17-18, ORL VIII: 373-374), Ramon explica que la razón del desacuerdo, oposición o contraste entre los cristianos y los infieles es la falta de concor- 
violenta de adoctrinamiento, evangelización o conversión forzadas, sino que su único objetivo era mostrar (verbo que tan solo designa la relación didáctica o pedagógica entre maestro y discípulo) al otro el contenido preciso de la propia fe mediante una "intervención gramatical de encaje entre sujeto y predicado" a fin de poder establecer unas bases sólidas y adecuadas para la disputa religiosa ${ }^{66}$.

\section{Conclusiones}

En las páginas precedentes hemos visto que el tema de las ideas de misión y cruzada en el pensamiento de Ramon Llull y de su relación con el islam en general ha sido estudiado a menudo desde enfoques en mayor o menor medida tendenciosos.

A menudo se ha querido ver en él un espíritu pacifista, respetuoso y tolerante con el que piensa diferente en materia de fe, buscando un modelo para el necesario diálogo intercultural e interreligioso actual. Llull sería, pues, un referente de nuestro pasado al que podemos mirar para afrontar mejor el reto al que nos enfrentamos en el mundo globalizado de hoy en día: la integración y convivencia de personas de culturas y religiones diferentes y la búsqueda de caminos de entendimiento, comprensión y respeto mutuos para evitar fanatismos religiosos. No obstante, conviene recordar, como hizo Cruz Hernández hace ya casi tres décadas, que no debemos incurrir en este tipo de proyecciones presentistas, pues "la trasposición de la realidad histórica del necesario encuentro cultural presente puede resultar terriblemente engañosa y anticientífica" ${ }^{67}$. La historiografía al respecto muestra una clara evolución desde esa imagen idealizada de Llull como modelo de pacifismo, tolerancia y diálogo interreligioso, hacia una visión

\footnotetext{
dancia entre lo que los cristianos entienden de sus proposiciones de fe ("Déus es en trinitat" o "Déus és encarnat", por ejemplo) y lo que los infieles entienden que creen los cristianos ("que cream en tres déus" o "que cream que la deïtat s'alteràs e morís", en relación a la Trinidad y la Encarnación). Así, "contrast és de nós a ells per çò com ells no entenen ço que nós creem", es decir, el problema es que los infieles "se cuiden que nós cream de l'A [Jesucristo] ço que no creem e no saben ço que de l'A [Jesucristo] creem e sabem", de modo que "per açò és lo contrast fet en lo predicat". Llull considera que "si ells entenien lo predicat segons que nós l'entenem, ells e nós no contrastaríem", de donde se deduce que, para que esto así sea, "lo papa e’ls prínceps deurien trametre missatge als infeels per donar a entendre del predicat ço que ells no entenen, per tal que ab la C [todos los cristianos] en lo subject e predicat se acordassen". Y dice que Jesucristo ha otorgado el poder a los cristianos para obligar a "alcuns sarraïns qui són catius e alcuns jueus" y para que "per força lur faça mostrar la nostra creença en qual manera creu en lo subject e en lo predicat" de forma que, así como el niño retiene la lección por miedo de su maestro, los infieles puedan aprender y entender por miedo a los cristianos. Johnston dice que "it is difficult to discover in this passage any indication of the courtesy, good-will, respect, or tolerance for non-Christians that some modern scholars find in Llull's arguments", aunque llega a la conclusion de que un análisis adecuado de las circunstancias y propuestas de Llull "ultimately undermines any claim that Ramon Llull's support for compulsory evangelization simply manifests the «religious intransigence» of a zealous proselytizer" (Johnston, "Ramon Llull and the Compulsory Evangelization...", pp. 15 y 36-37).

66 Perarnau i Espelt, “Consideracions...”, pp. 568ss y "Certeses, hipòtesis i preguntes...”, pp. 490-491.

67 Cruz Hernández, "El símbolo del árbol en Ramón Llull...”, p. 25.
} 
menos apasionada y mejor contextualizada ${ }^{68}$. Si bien es cierto que Llull, en comparación con otros pensadores y tratadistas de su época, puso un mayor énfasis en las armas intelectuales y espirituales que en las armas corporales o materiales, pudiendo situarle por tanto en la línea del "criticismo de las cruzadas"69, no podemos afirmar, como tantas veces se ha hecho, que en su pensamiento haya un rechazo radical de la cruzada, pues ésta también tuvo un lugar dentro de sus planes misioneros.

Ante sus aparentemente múltiples y cambiantes opiniones, autores como Sugranyes de Franch o Hillgarth pretendieron salvaguardar el espíritu pacífico y dialogante de un Ramon que siempre habría mirado con reservas la cruzada armada y que, cuando la integró

68 Introduzco esta nota para aclarar una cuestión que, como me señala uno de los revisores anónimos, podía ser confusa. En algunos lugares del texto, mi redacción parecía calificar de ingenuos o acientíficos a los enfoques que subrayan el valor del ejemplo luliano para reflexionar y replantear el debate contemporáneo en torno a problemas como el de las relaciones interreligiosas. No era esa mi intención: son lícitos, por supuesto, los discursos que pretenden hacer valer una lectura actual de Llull útil a los problemas sociales contemporáneos, tratando de mostrar lo que el pensamiento del mallorquín tiene que decir y que ofrecer al hombre del siglo XXI. Yo mismo, en un coloquio reciente de homenaje a Rafael Ramón Guerrero (Oporto, 6-8/02/2020), hablé del valor del pensamiento luliano para la reflexión contemporánea sobre la razón (artículo que aparecerá próximamente con el título: "Per scientiam amantiam cognoscere et per amantiam scientiam diligere. Intelecto y afecto, conocimiento y amor, razón y corazón en el pensamiento medieval"). Efectivamente, creo que una parte importante de nuestra misión como medievalistas consiste en mostrar al hombre de hoy el valor y la riqueza que el pensamiento medieval entraña para la reflexión actual sobre determinados temas. El primer párrafo de este artículo subraya esa idea: "estudiar las relaciones entre las grandes identidades religiosas en el mundo premoderno puede ser enriquecedor para nuestra comprensión de las mismas y de gran provecho para el planteamiento de los cauces por los que puede discurrir una mejor relación entre ellas en la actualidad". Ahora bien, no es lo mismo traer al presente el ejemplo de un autor del siglo XIII como Llull para sugerir líneas de reflexión en torno a problemas contemporáneos, que interpretar a ese autor del siglo XIII a la luz de los problemas y exigencias de nuestra sociedad. Por supuesto que es enriquecedor, aconsejable y necesario que volvamos nuestros ojos hacia el pasado a la hora de pensar nuestros problemas actuales, porque, en el fondo, la historia de la humanidad no es sino el despliegue en el espacio y en el tiempo de una experiencia humana que, en lo fundamental, es común a toda época: la búsqueda del significado y sentido de la vida a partir de una serie de exigencias innatas, y la búsqueda de modelos de vida en común adecuados. La historia es el espacio en que los diferentes pueblos, culturas, sociedades y sujetos han emprendido su particular búsqueda del significado de las cosas y de la existencia y han desarrollado y ensayado sus propias hipótesis explicativas, de modo que el estudio histórico se convierte en un lugar en que convergen las diversas hipótesis explicativas y certezas intersubjetivas (las de cada civilización, época, cultura o sujeto), que podemos confrontar con las nuestras propias. La posibilidad de confrontar nuestra experiencia, preguntas e hipótesis presentes con las de los hombres y pueblos del pasado es una de las mayores virtudes que tiene la Historia como rama de estudio. En este sentido, preguntarse qué tiene que ofrecernos el pensamiento de Llull a nosotros, hombres del siglo XXI, es totalmente lícito y enriquecedor. Lo que en mi artículo pretendía cuestionar son aquellas lecturas que pretenden explicar el pensamiento de Llull desde parámetros, categorías y sensibilidades actuales. Lo que defiendo es que desde esas primeras lecturas idealizadas y presentistas (apartado 2.1), se ha producido una evolución del discurso en torno a Llull que pasó por una fase todavía "muy positiva" (2.2), luego por un momento de crítica y cuestionamiento (2.3) - no siempre libre de prejuicios o de postulados puramente ideológicos (véase, en mi opinión, Barceló)—, para finalmente, superadas las críticas, llegar a una comprensión más global y, en mi opinión, acertada del pensamiento de Llull sobre misión y cruzada (2.4).

69 Véase Throop, Criticism of the Crusade...; Wheeler, The Problem of the Saracen Infidel... y Siberry, "Missionaries and Crusaders..." y Criticism of Crusading 1095-1274. 
en sus planes, siempre lo hizo como un instrumento al servicio de la misión al que sería lícito recurrir solo en caso de que fuera estrictamente necesario para garantizar la libre predicación misionera. Autores posteriores, como Urvoy, Kedar o Barceló, defendieron que la evolución de las ideas de Llull ponía de manifiesto una contradicción entre un proyecto idealista inicial, gestado en una situación de superioridad frente al islam dominado balear, y una visión más realista a partir del encuentro real, crudo y duro, con la comunidad musulmana no dominada del norte de África. Así, Ramon habría perdido la inocencia y el idealismo utópico del comienzo para terminar abrazando del todo la cruzada como pilar necesario y fundamental de la tarea misionera, pero es que, además, su rechazo de la misma no habría sido tan claro ni siquiera en sus primeras obras. La cuestión, no obstante, no quedaba del todo resuelta: ¿cómo entender entonces que Llull condenase tan duramente la cruzada y la caballería mundana en algunos pasajes, que en otros combinase la predicación y la argumentación racional con el uso de la fuerza y que, por último, escribiese minuciosos tratados sobre cómo reconquistar Tierra Santa?

A partir de mediados de los años noventa, autores como Beattie, Gayà, Domínguez Reboiras o Perarnau i Espelt, superando la polarización del debate, intuyeron que los planes de cruzada de Llull solo cobrarían sentido completo en el conjunto total de su pensamiento y que había que elevarse desde el análisis de los textos particulares hasta un estudio de conjunto que tuviera en cuenta tanto el contexto de la realidad histórica de la cruzada como la inclinación global del pensamiento del mallorquín. Las ideas lulianas de misión y cruzada necesariamente han de ser estudiadas como partes integrantes - nunca de forma aislada - de un pensamiento unitario y coherente acerca de la sociedad y el ser humano, de la finalidad para la cual fue creado y de los instrumentos de que dispone para alcanzarla — principios antropológicos sobre los que Llull construye sus propuestas misioneras y cruzadísticas que han de ser buscados no tanto en los tratados de cruzada como en el conjunto de su obra-. Cualquier otro enfoque de la cuestión basado en el análisis de un repertorio más o menos selectivo de textos lulianos aparentemente a favor y en contra del recurso a la fuerza en la conversión de los infieles y que no tenga en cuenta una visión global del pensamiento del mallorquín, resulta parcial e incompleto y lleva, necesariamente, a interpretaciones insuficientes que no logran captar toda la profundidad y complejidad del asunto ${ }^{70}$.

Si bien este último grupo de autores ha indicado el camino a seguir, aún sigue siendo necesario un estudio sistemático y en profundidad de las ideas lulianas de misión y

\footnotetext{
70 Algunos han seguido subrayando la figura de Llull como modelo de diálogo interreligioso que puede sernos de gran utilidad hoy en día para gestionar la diversidad cultural de nuestra sociedad (OLIVER, "Ramon Llull. Una tienda de encuentro..."; PINDL, "Ramon Llull, protagonista del diálogo...” y Marín I Torné, "El diàleg islamocristià", "Religions en diàleg...", "Ramon Llull: Creure i entendre...” [de deliciosa lectura], "L’islam i el diàleg interreligiós" y "Un Mediterrani cosmopolita..."). En el polo opuesto, encontramos a autores que, preocupados por desmontar esa idílica visión, presentan síntesis describiendo la evolución del mallorquín desde un inocente e idealista irenismo inicial, hasta una más realista aceptación de la imposibilidad de convertir a los infieles sólo mediante su complejo Ars y de la necesidad de emplear la fuerza (Egea i Ger, "Ramón Llull: del combate espiritual...,, Tolan, Saracens..., pp. 256-274 y Porsia, Progetti di crociata...). En sus trabajos, además, no encontramos importantes novedades.
} 
cruzada que tenga en cuenta toda la bibliografía existente al respecto y que tome en consideración la obra de Llull en su totalidad. Para ello, me gustaría señalar tres indicaciones básicas a seguir.

En primer lugar, habría que estudiarlas integradas dentro de la globalidad de su pensamiento acerca del ser humano, del fin o primera intenció para el cual Dios lo ha ordonat y de los medios de que dispone para ello. El deseo ideal último de Llull era "ad bonum statum reducere uniuersum et ad unum ouile catholicum adunire" 71 , es decir, reconducir o elevar a la humanidad desde el mal estado en el que ha caído hasta un buen estado en el que el ser humano pueda caminar por la vía de la verdad, estar en paz y alcanzar la finalidad para la cual fue creado: entender, amar, recordar, honrar, servir, loar y bendecir a Dios ${ }^{72}$. En esta misión de elevar el mundo desde su malum statum hasta un bonum statum tan importante era la conversión de los infieles — mediante la evangelización misionera, que podría ser facilitada por la cruzada - como la unidad de los cristianos — regreso de cismáticos y herejes al ovil católico - y como la reforma moral y social de la cristiandad. La conversión de los infieles sería, así, el reflejo externo de la conversión que toda la cristiandad debería experimentar. Misión y cruzada —inseparables y de la mano- - por una parte, y unidad y reforma de la cristiandad, por otra, eran el reverso y el anverso de una moneda cuyo valor total era la consecución de un bonum statum en el que todos los hombres viesen cumplida su finalidad última y, así, pudiera verse realizado el plan divino para sus criaturas [fig. 1].

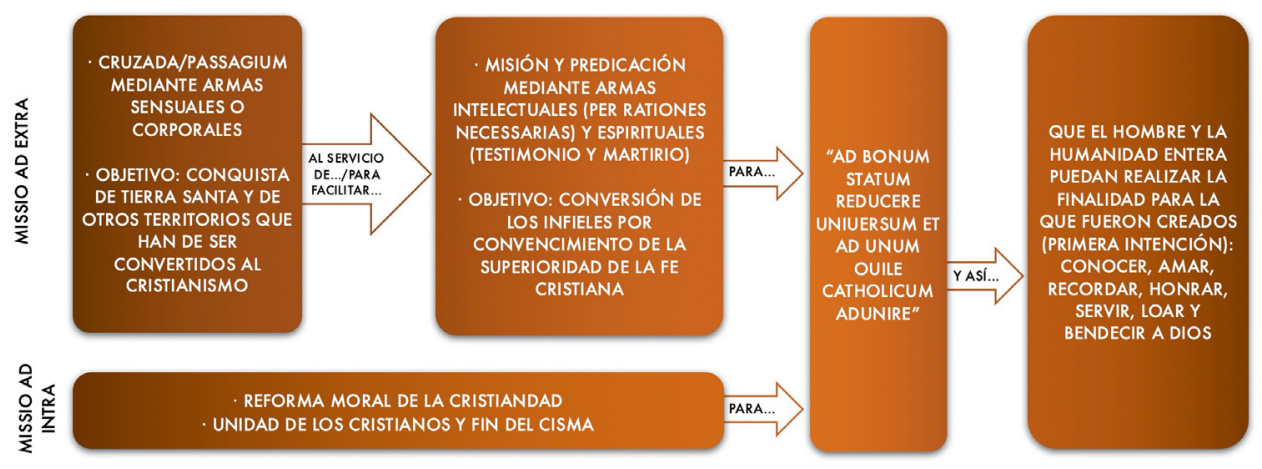

Fig 1. Esquema de finalidades en el pensamiento misionero y reformista de Llull (elaboración propia).

\footnotetext{
${ }_{71}$ Liber de fine (ROL IX: 251). No es baladí que su más largo y detallado libro sobre la misión y la cruzada se titule De fine, con un triple significado: el fin último hacia el que debería tender cada ser humano, como criatura, y la humanidad, como creación; el fin al cual Llull había consagrado su vida, y, por último, el fin en un sentido escatológico.

72 Arbre de ciència (1295-96; ORL XI: 329) y Llibre de coneixença de Déu (1300; ORL II: 375).
} 
En segundo lugar, sus ideas acerca de misión y cruzada han de ser estudiadas siempre dentro del contexto histórico, cultural, social y político del momento en el que vivió Llull. Sería absurdo pretender entender a Llull fuera de su realidad o tomándolo como un personaje totalmente único para su época: sólo la consideración de sus ideas enmarcadas dentro su contexto y en constante diálogo con otros personajes y corrientes de pensamiento puede llevarnos a la correcta y completa comprensión del significado y la originalidad de sus planteamientos.

En este sentido, considero que hemos de superar la infértil dicotomía historiográfica que entiende misión y cruzada como conceptos o realidades antagónicas y excluyentes: la simple lectura de los escritos de Llull muestra cómo en su pensamiento evangelización, cruzada y reforma son realidades entrelazadas y plenamente integradas. Si Llull siempre privilegió la misión espiritual e intelectual fue porque estaba realmente convencido no sólo de que era posible lograr la conversión de los infieles por convencimiento racional de la superioridad de la fe cristiana, mediante armas intelectuales, y siguiendo el método de los apóstoles, sino también de que ésta era la vía más eficaz y más acorde con la caridad cristiana ${ }^{73}$. Precisamente debido a esa convicción, en el plan misionero de Llull el ideal prioritario fue siempre la libre conversión de los infieles a través de la predicación racional y el testimonio, mientras que el uso de la fuerza sensual o corporal — tanto en la organización de una cruzada como en la práctica de obligar a judíos y musulmanes a escuchar las prédicas cristianas-, se reducía a una primera intervención cuyo fin no era la conversión sino únicamente garantizar la recepción del mensaje $\mathrm{e}^{74}$.

73 Véanse los textos citados más arriba, en las notas 18-22.

74 Así lo muestra Perarnau i Espelt, "Certeses, hipòtesis i preguntes...”. Según Llull, para lograr la paz entre los cristianos y los musulmanes y poner fin a los grandes males derivados de la guerra, primero es necesario que haya paz sensual o material, para dar paso después a una 'guerra intelectual' en la que los cristianos puedan iluminar a los sarracenos en el camino de la verdad. Concluida esta 'guerra intelectual', se habría alcanzado una paz y concordancia definitivas entre cristianos y musulmanes, pues tendrían una misma fe y creencia: "\$24. On, com hom es vengut a assò, Sènyer, que hom es en guerra ab son enemic entellectualment e sensualment, qui vol aver pau encerc la en les coses entellectuals primerament e fassa la potencia racional dona de la potencia sensitiva, e si hom nos pot posar ab son enemic en les coses entellectuals, encerc la pau en les coses sensuals mortificant a aquelles lur forsa e lur natura, car per lur venciment e mortificament se posa hom es pacifica en la entellectual natura. \$25. Senyor amat, Senyor honrat, Senyor temut! Com sia cosa que los crestians e los sarrayns guerregen entellectualment en so que no sacorden nes convenen en fe ni en creensa, per assò, Sènyer guerrejen sensualment, per la qual guerra esdevenen los homens nafrats e cativats e morts e destruíts, per lo qual destruiment son gastades e malmeses molts principats e moltes riquées e moltes terres, e son cessats molts de bens quis faríen si la guerra no era. $\S 26$ On, qui vol metre pau enfre los crestians e los sarrayns e vol cessar los tan grans mals qui hi esdevenen per lur guerra, primerament, Sènyer, cové que hom meta pau en la sensual natura per tal que los uns pusquen anar e esser entrels altres, e per la pau sensual porá hom concordar la guerra entellectual; e pus la guerra entellectual sia fenida, adoncs será pau e concordansa enfre ells per so car aurán una fe e una creensa, la qual unitat de fe e de creensa será occasio e rao com ajen pau sensualment. §27. Mas com los crestians, Sènyer, no an pau sensualment ab los sarrayns, per assò nos gosen esputar en la fe ab ells com son enfre ells; mas si avíen pau sensualment e podíen los uns esputar ab los altres de la fe sens guerra sensual, adoncs sería possíbol cosa quels crestians endressassen e illuminassen los sarrayns a via de veritat per gracia de Sant Espirit e per veres raons significades en lo acabament de les 
Así, en el problema del infiel, la primera intención o finalidad última se identifica con su conversión, pero nunca con su aniquilación, y la guerra, en tanto que medio instrumental, entraría dentro de la órbita de la segunda intención.

De este modo, si Llull se mostró crítico con la cruzada no fue porque condenase el uso de las armas en sí mismo, en abstracto: la caballería, nos dice, no es mala y, de hecho, fue instituida por Dios para remediar el malum statum en que había caído el mundo ${ }^{75}$; el problema es que también la caballería ha caído en ese malum statum generalizado, provocado por el olvido de su 'primera intención' o verdadero propósito de su existencia. Lo que condenaba Llull era precisamente que los dirigentes de la cristiandad hubieran olvidado la 'primera intención' que debía regir sus vidas y cualquier acción dirigida ad infideles y hubiesen centrado todos sus esfuerzos en conseguir vanas glorias mundanas (las tierras y riquezas de los infieles y, para ello, su muerte). Así, Llull no criticó la cruzada en sí misma, sino la perversión de ésta por el modo en que papas, príncipes y caballeros cristianos las estaban llevando a cabo ${ }^{76}$. Cruzada y caballería, en el fondo,

vostres qualitats. §28. Celestial Senyor, Pare de iots temps! Com vos, Sènyer, trametés la persona del Fill pendre carn humana tan solament, adoncs aguès pau sensualment vos els apostols els dexebles ab los jueus e ab los fariseus e ab les autres gents; car anc vostre cors ni anc los vostres apostols no preseren ne aucieren ne forsaren sensualment negú daquells homens quius descreyen e qui vos els vostres apostols perseguíen, e per assò esdevencse que vos els apostols els dexebles amàs pau sensual per tal que aquells quj eren en via de error aguessen pau entellectual en gloria. \$29. On, enaxí com vos els vostres apostols e devebles aguès pau sensual, Sènyer, en so que no guerrejès sensualment jassía que hom vos feés guerra sensual, enaxí sería molt gran raó que los crestians remembrassen la manera que vos prenguès ab los apostols e que anassen aver pau sensual ab los sarraíns per tal que poguessen donar laor e gloria de vos qui mortificant la natura sensual aportàs pau en terra entellectual. §30. Mas com la fervor e la devocio qui era en los apostols e en los sants homens sè enrere no sia en nosaltres e quax tot lo mon se sia refredat e ublidat damor e de devocio, per assò, Sènyer, me par quels crestians fan forsa en guerra sensualment molt majorment que en la entellectual, e per la paor de la guerra sensual no volen anar metre pau en la natura entellectual en aquella manera segons la qual la tractàs vos els apostols escampant lagremes e plors e suspirs e amors e sanc preciosa e mort angoxosa, donant gloria e laor de vos qui sots nostre Senyor Deus" (Llibre de contemplació en Déu, c. 204, 24-30; ORL V: 310-318).

75 A la caballería dedica todo un tratado en que explica su naturaleza y propósito: el Llibre de l'orde de cavalleria.

76 Numerosos textos transmiten esa idea de que, si los príncipes, papas y caballeros cristianos amasen más a Dios que a las cosas mundanas, se lograría la conversión de los infieles y la conquista de Tierra Santa. Véanse, a modo de ejemplo, estos pasajes del Llibre de contemplació en Déu: "Si vos, Sènyer, fossets en ésser per home e que home fos per sí metex, fora bo que home fos honrat sobre vos; mas com assò no sia enaxí, e com vos ajats creat home per honrar més vos que sí metex, doncs, com es home tan desastruch que més ama membrar e honrar sí metex que vos? ni com pot ésser quel papa els cadernals els religiosos els prelats els prínceps, lo poder quels avets donat en honrar vos nol meten en vostre honrament? Car daitant com ells an lo poder en honrar vos e no usen daquell, daitant vos fan ésser desonrat en lo sant loc de Jherusalem e en lo cor dels homens infeels qui en falses prophetes creen e qui ydoles e serps adoren e honren a semblansa com si eren aquelles coses deu creador nostre" (c. 284, §24; ORL VII: 150); "Car si los crestians amaven lonrament de nostra dona segons lo poder que an d amar en potencia, serien, Sènyer, actualment tan fortment remembrants e entenents en nostra dona e en sos honraments, que tal seria la amor e la volentat que li auríen que lo sant loc on nasc nostra dona e lo sant loc on concebé de Sant Espirit e lo sant sepulcre on nostra dona esquinsà sos vestiments e tirà sos cabells e escampà ses làgremes per lescampament de la sanc de son Fill gloriós, aquells locs serien dels crestians e seria y honrada nostra dona e son Fill gloriós en aquell loc on nostra dona fo tan aontada e son Fill tan turmentat" (c. 287, §17; 
eran dos de los muchos aspectos de la cristiandad que necesitaban ser reformados, reeducados y reducidos ad bonum statum, hacia su 'primera intención'. Por otro lado, la cruzada militar mediante 'armas sensuales o corporales' siempre fue considerada en el pensamiento luliano inferior a la misión mediante 'armas intelectuales o espirituales', pues, por la dimensión material que tiene, comporta un riesgo mayor de que los caballeros se vanaglorien con victorias y riquezas y acaben confundiendo por completo la 'primera intención' que debía dominar en la gestión del 'problema del infiel'.

Desde este punto de vista, no habría en el pensamiento de Llull ni contradicciones ni "many opinions", ni tan siquiera una evolución, un cambio profundo de parecer o una cuestión de acento, como han sugerido diferentes autores. Si entendemos que para Llull cruzada y misión no son realidades opuestas ni excluyentes, sino instrumentos complementarios - el primero subordinado al segundo - para lograr la conversión de los infieles, y que jamás rechazó la cruzada como tal, sino que lo que condenó severamente es la perversión de la misma y el olvido por parte de los poderes de la cristiandad del ideal o 'primera intención' que debía regir la acción misionera ad infideles, así, los tratados y peticiones que escribió sobre el passagium no suponen cambios de actitud o de pensamiento, sino únicamente intentos - motivados por los cambios políticos de la época - de presentar a los poderes de la cristiandad sus planes misioneros y reformistas.

ORL VII: 178-179), y "§22. Etemal Senyor gloriós sens fi e sens comensament! La .vij. ${ }^{a}$ raó se diu en los princeps e en los cavallers e en lo poble dels crestians. On, deym que sensualment sentim e entellectualment entenem que los princeps els cavallers e lur poble an poder e saber de conquerre lo Sant Sepulcre de Jherusalem e tots los altres locs que los sarrayns e los infeels posseexen; mas car lur voler, Sènyer, es defallent e no ama vos acabadament, per assò es major lo poder el saber que vos lur avets donat, que lo voler quels avets ordonat com francament vulla esser de la quantitat del poder el saber, lo qual ordenament avets fet ab la vostra preciosa sanc que escampàs per amor que nos altres escampassem la nostra per la vostra amor. [...] \$24. On, beneyt siats vos, Senyor Deus: car si vos forsavets lur voler que fos tan gran en fer bé com es lur poder e saber, seria costret lo franc voler, e pus fos costret auría perdut lacabament al qual vé per voler francament segons lacabat e poder e saber; e car vos no sots contrari a nulla vostra creatura e majorment al voler humà qui es de mellors creatures qui sien per creació, doncs per assò avets vos volgut esser home e murir per home, per tal que nostre voler tot franc per vos a amar, vulla usar del poder e del saber que vos avets a home. Mas car lo voler dels malvats princeps e dels malvats sotsmeses lurs se sia girat en peccats e en defalliments, per assò per defallent voler no pot lo poder ni no sab lo saber dels crestians endressar ni donar tot lo mon a la sancta fe romana" (c. 309, $\$ 22$ y 24; ORL VII: 419420). Es clarificador el siguiente pasaje del Llibre d'intenció: "Mas lo demoni tempta los xrestians en les dues intencions, per tal que amen lur mort per la segona intenció, e les terres e les riqueses quels infisels posseexen, per la primera. On, sapies, fill, que temptació diabolical per absencia de fe e de esperança, de caritat, de prudencia e de fortitudo, e per presencia d'avaricia e de accidia e de envetgya, fa molt de mal en lo mon en desviar intenció d'aquelles coses per que son. Per la primera intenció, fill, és amable la conversió e lo convertiment dels infeels, e per la segona és amable guerra e batalla contra los infeels. E per açò, fill, los xrestians deurien pus fortment continuar e usar de la primera intenció en los infeels, que de la segona; e car no ho fan, és injuriada la primera intenció, e a la segona és feta major honor que no és convé. Amable fill, la major e la pus alta entenció que hom pot haver a multiplicar fe e esperança, e les altres virtuts, es haver intenció de donar conexença de Deu e amor als infeels qui·l ignoren e no·l amen; e per aquesta tan alta itnenció son tant altament pujats en santetat e en gloria los apòstols e els màrtirs. On, com açò sia en axí, donchs, fill, quant serà aquell temps que entenció sia en los honraments en que esser solia?" (Llibre d'intenció, c. 20, §2-4; ORL XVIII: 47-48). 
En tercer lugar, han de evitarse a toda costa planteamientos presentistas tales como la caracterización de Ramon Llull como un 'pacifista universal', 'promotor del diálogo interreligioso', 'defensor de la libertad de conciencia y creencia' o similares, pues trasladar al pasado el necesario encuentro intercultural e interreligioso actual, buscando un referente pasado idealizado, puede resultar terriblemente engañoso y anticientífico. De igual modo, hemos de evitar juzgar a Llull en base a lo que hoy día nos parecería moralmente adecuado en relación con la diversidad religiosa (no olvidemos, por otro lado, que tampoco hoy existe un consenso en estos delicados temas). Así, cuidémonos de calificar al mallorquín - y hago extensible esta apreciación a cualquier personaje de la Edad Media - de integrista religioso, intolerante fanático o ardiente proselitista, como en ocasiones se ha hecho ${ }^{77}$. Un ardor misionero como el que floreció en el siglo XIII, y del que Llull es buena muestra, puede resultar hoy día, para algunos, incompatible con el reconocimiento y respeto de la diversidad de creencias, y hasta agresivo y violento, pero no podemos olvidar que la libertad religiosa y el resto de cuestiones derivadas de la conciencia de la diversidad han sido una conquista histórica o aprendizaje reciente. Para un hombre medieval con una religiosidad como la de Llull no había nada tan provechoso para la construcción del reino de Dios en la tierra - es decir, para Dios, para la Iglesia, para el mundo, para los cristianos y los no cristianos y para uno mismo - como extender la fe y predicar la verdad que se creía poseer. Llull tenía la más decidida voluntad de "endressar los errats a via de veritat" 78 , esto es, de convertir a los errados — cismáticos e infieles, especialmente los musulmanes - al cristianismo, la vía de la verdad, y lo que le diferencia de otros pensadores es su firme confianza en el método de la razón y en la propia superioridad racional de la verdad del cristianismo. En fin, no podemos aplicarle, ni en positivo ni en negativo, una noción de tolerancia o respeto interreligioso al estilo contemporáneo; es más, no deberíamos siquiera sentir la necesidad o el impulso de contrastar a un personaje del siglo XIII con los esquemas morales de nuestra sociedad actual.

En el presente trabajo de investigación hemos comprobado cómo el tema de las ideas de misión y de cruzada en el pensamiento de Ramon Llull aún requiere un estudio profundo y sistemático. La revisión bibliográfica que hemos realizado muestra las debilidades y puntos fuertes de las diferentes corrientes de interpretación y demuestra que los escollos con los que se ha topado la investigación siguen afectando a publicaciones recientes principalmente por desconocimiento real de las fuentes y de la amplia bibliografía que hay_-, al tiempo que sugiere una posible hoja de ruta para esquivarlos. Estos escollos son tres: estudiar la cuestión de la misión y la cruzada de forma aislada, como si fuese un compartimento estanco del pensamiento luliano que pueda ser desgajado del mismo,

\footnotetext{
77 Colomer habla de "intransigencia religiosa" (Colomer i Pous, "Ramón Llull y el judaísmo...”, p. 39); Colom Ferrá de un "ardiente proselitismo" (COLOM FERRÁ, "Ramón Llull y los orígenes de la literatura...", p. 144), y Barceló sitúa a Llull entre los "clérigos fanáticos y obcecados” (BARCELó, "«Per sarraïns a preïcar"...", p. 130).

78 Llibre de contemplació en Déu (1273-1274), c. 106, § 23 (ORL IV: 24). En otro lugar escribe: "Convertir es endressar los errats a via de veritat, per ésser participants ab los cathòlics en vida perdurable", Doctrina pueril (1274-1276), c. $83 \S 1$ (ORL I: 154).
} 
perdiendo de vista la totalidad, coherente y unitaria, de su filosofía; construir el análisis a partir de la moderna oposición de los conceptos de misión y cruzada, como si en la Edad Media hubiesen sido realidades contrarias o excluyentes, cuando en realidad fueron instrumentos complementarios al servicio del ideal de convertir a los infieles y de cristianizar el mundo, como vemos en el pensamiento de Llull y en otras figuras del contexto histórico y cultural de finales del siglo XIII y comienzos del XIV, y, por último, partir de planteamientos presentistas que terminan juzgando a Llull según los parámetros y criterios culturales actuales, ya sea para ensalzarlo como paladín del pacifismo, promotor de la tolerancia y el diálogo y defensor de la libertad religiosa, o para denigrarlo como integrista religioso. Si nos liberamos de estos prejuicios presentistas y estudiamos las ideas del mallorquín de misión y cruzada dentro del contexto histórico y cultural de la época e integradas dentro del conjunto global de su filosofía, podremos caminar hacia una comprensión más adecuada del pensamiento misionero y cruzadista de Ramon Llull.

Un futuro estudio sobre este tema habrá de comenzar por algunas de las primeras obras de Llull —como el Llibre de contemplació en Déu (1273-74), la Doctrina pueril (1274-1276), el Romanç d'Evast e Blaquerna (1276-83) o el Llibre de meravelles (1287-89)_, en las que ya están expuestos y desarrollados los elementos principales de su unitario y coherente ideario acerca de la manera de reeducar el mundo ad bonum statum mediante la reforma, la misión y la cruzada; hasta llegar a sus tratados propiamente cruzadistas, sin perder de vista la totalidad de su producción escrita, en toda su diversidad de géneros, estilos, contextos y destinatarios. Semejante investigación posiblemente pueda conducirnos a conclusiones más completas y complejas que las que hasta ahora se han esgrimido acerca de cuál era según Ramon Llull la mejor manera de afrontar el 'problema del infiel' y de regular las relaciones con los mundos no cristianos.

\section{Bibliografía ${ }^{79}$}

Alòs Moner, R. D., "Idees lul·lianes de comunitat universal”, en VV. AA., Miscel·lània Patxot: estudis de dret public, Llibreria Verdaguer, Barcelona, 1931, pp. 35-47.

Altaner, B., "Glaubenszwang und Glaubensfreiheit in der Missionstheorie des Raymundus Lullus. Ein Beitrag zur Geschich-te des Tolleranzgedankens", Historisches Jahrbuch der Görres-Gesellschaft, 48 (1928), pp. 586-610.

Altaner, B., "Raymundus Lullus und der Sprachenkanon (can. 11) des Konzils von Vienne (1312)", Historisches Jahrbuch der Görres-Gesellschaft, 53 (1933), pp. 190-219.

\footnotetext{
79 Abreviaturas de revistas: AST = Analecta Sacra Tarraconensia: revista de ciencias históricoeclesiásticas (Barcelona, d. 1925); ATCA = Arxiu de Textos Catalans Antics (Barcelona, d. 1982); BSAL = Bolletí de la Societat Arqueologica Lul-liana (Palma, d. 1886); EF = Estudios Franciscanos / Estudis Franciscans (Barcelona, 1907-36 y d. 1948); EL = Estudios Lulianos (Palma, 1957-90); y SL = Studia Lulliana (Palma, d. 1991; continuación de EL).
} 
AlvirA, M., "Conquista y reconquista en la Corona de Aragón (1162-1276)", en C. de Ayala Martínez, I. C. Ferreira Fernandes y J. S. Palacios Ontalva (coords.), La Reconquista. Ideología y justificación de la Guerra Santa peninsular, La Ergástula, Madrid, 2019, pp. 187-229.

Artus, W. W., “The Philosophical Understanding of Ramon Lull's «rationes necessariae»", Antonianum, 62 (1987), pp. 237-270.

Ayala Martínez, C. de, Las Cruzadas, Sílex, Madrid, 2004.

Ayala Martínez, C. de, "Órdenes militares y guerra santa. Reconquista y cruzada en el occidente peninsular (siglos XII-XV)”, en M. Ríos Saloma (ed.), El mundo de los conquistadores, Universidad Nacional Autónoma de México-Sílex, México-Madrid, 2015, pp. 355-373.

Ayala Martínez, C. de, "La Reconquista: ¿ficción o realidad historiográfica?”, en Á. Gordo Molina y D. Melo Carrasco (coords.), La Edad Media peninsular. Aproximaciones y problemas, Ediciones Trea, Gijón, 2017, pp. 127-142.

BADIA, L., Teoria i pràctica de la literatura en Ramon Llull, Quaderns Crema, Barcelona, 1992.

Ayala Martínez, C. de, "Ramon Llull: Autor i Personatge", en F. Domínguez, R. Imbach, T. Pindl-Büchel y P. Walter (eds.), Aristotelica et Lulliana magistro doctissimo Charles Lohr septuagesimum annum feliciter agenti dedicata, Abbatia Sancti Petri / Martinus Nijhoff International, Steenbrughe / La Haia, 1995, pp. 355-375.

BArber, W. A. T., Raymond Lull, the illuminated doctor. A study in mediaeval missions, Londres, 1903.

BARCELÓ, M., “«Per sarraïns a preïcar» o «l'art de predicar a audiènces captives»”, Estudi general, 9 (1989), pp. 117-132.

BAtllori, M., Ramon Llull en el món del seu temps, Dalmau, Barcelona, 1960.

BAtLlori, M., "Introducción», en Ramon Llull. Obra Escogida, Alfaguara, Madrid, 1981, pp. xi-lxxxix.

BAtLlori, M., "Introducción: Ramon Llull. El hombre, el pensador, el poeta", en Ramon Llull. Obra escogida, Penguin Random House, Barcelona, 2016, pp. ix-xlvi.

BAUZÁ y BAUZÁ, R., "Doctrinas jurídicas internacionales de Ramon Llull. La guerra y la paz (concepción luliana)", EL, 13 (1969), pp. 37-49.

BeATtie, P., Evangelization, reform and eschatology: mission and crusade in the thought of Ramon Llull [tesis doctoral], University of Toronto, 1995a.

Beattie, P., "«Pro exaltatione sanctae fidei catholicae». Mission and crusade in the writings of Ramon Llull", en L. J. Simon (ed.), Iberia and the Mediterranean World of the Middle Ages. Studies in Honor of Robert Burns S. J., Brill, Leiden, 1995b, pp. 113-129. Beattie, P., "Eschatology and Llull's «Llibre contra Anticrist»”, SL, 37 (1997), pp. 3-24. Beattie, P., "Crusading and the Penitential Life: James of Vitry's Crusade Sermon Models and Llull's De fine", SL, 54 (2014), pp. 33-66. 
Beattie, P., "Ramon Llull's Crusade Treatises", en A. M. Austin y M. D. Johnston (eds.), A Companion to Ramon Llull and Llullism, Brill, Leiden, 2018, pp. 176-214.

Bonner, A., “L'apologètica de Ramon Martí i Ramon Llull davant de l'Islam i del judaisme”, Estudi General, 9 (1989): 171-185.

Bonner, A., "Reducere auctoritates ad necessarias rationes", en M. I. Ripoll (ed.), Actes de les Jornades Internacionals Lul-lianes. Ramon Llull al s. XXI. Palma, 1, 2 i 3 d'abril de 2004, Universitat de les Illes Balears / Universitat de Barcelona, Palma / Barcelona, 2005, pp. 47-73.

Bonner, A., The Art and Logic of Ramon Llull: A User's Guide, Brill, Leiden-Boston, 2007.

BonNer, A., "La disputa interreligiosa, la solución ingeniosa de Ramon Llull", Quaderns de la Mediterrània, 9 (2008), pp. 362-368.

Bonner, A. y BAdiA, L., Ramon Llull. Vida, pensament i obra literària, Empúries, Barcelona, 1988.

Bronisch, A., Reconquista y Guerra Santa. La concepción de la guerra en la España cristiana desde los visigodos hasta comienzos del siglo XII, Universidad de Granada, Granada, 2007.

BRUMmer, R., “L'enseignement de la langue arabe à Miramar: faits et conjectures”, EL, 22 (1978), pp. 37-48.

Brummer, R., “Una qüestió debatuda: Ramon Llull va escriure llibres en àrab?”, en VV. AA., Estudis de llengua i literatura catalanes / XI. Miscel-lània Antoni M. Badia i Margarit, vol. 3, Publicaciones de l'Abadia de Montserrat, Barcelona, 1985, pp. 55-70.

Burns, R. I., "Christian-Islamic Confrontation in the West: The Thirteenth-CenturyDream of Conversion”, The American Historical Review, 76 (1971), pp. 1.386-1.434.

Caldentey Vidal, M., "La paz y el arbitraje internacional en Ramón Lull (Raimundo Lulio)", Verdad y Vida, 1 (1943), pp. 456-485.

Calpe Melendres, X. "La relación intelecto-voluntad en el método misionológico luliano. Las razones necesarias y los motivos para aceptarlas o rechazarlas", en L. M. Nontol y R. RAmis Barceló (eds.), Ramón Llull y el lulismo: contemplación y acción, Sindiéresis, Madrid-Oporto, 2019, pp. 137-167.

Cardini, F., Minima mediaevalia, Arnaud, Florencia, 1987.

CARDini, F., Studi sulla storia e sull'idea di crociata, Jouvence, Roma, 1993.

CARDInI, F., "Raimondo Lullo e la crociata. Alcune considerazioni alla luce del rapporto fra crociata e missione nei secoli XII-XIV”, 2007 [texto inédito que el prof. Cardini me ha facilitado gentilmente vía correo electrónico; 12 pp.].

Carreras i Artau, T. y Carreras i Artau, J., Historia de la filosofía española. Filosofía cristiana de los siglos XIII al XV, t. I, Real Academia de Ciencias Exactas, Físicas y Naturales, Madrid, 1939. 
Civezza, M. da, Storia universale delle missione Franciscane, t. II. Tipografia Tiberina, Roma, 1858, pp. 575-599.

Cofresi, L. L., "Reason and Revelation: the Coincidence of opposites in Ramon Llull's Thought", EL, 24 (1980), pp. 211-214.

Coll, J. M., "Escuelas de lenguas orientales en los siglos XIII y XIV (Periodo Raymundiano)", AST, 17 (1944), pp. 115-138.

Coll, J. M., "Escuelas de lenguas orientales en los siglos XIII y XIV (Período postraymundiano)", AST, 18 (1945), pp. 59-88.

Coll, J. M., "San Raymundo de Peñafort y las misiones del Norte Africano en la Edad Media", Missionalia hispanica, 5 (1948), pp. 417-457.

Colom Ferrá, G., "Ramón Llull y los orígenes de la literatura catalana”, EL, 13 (1969), pp. 133-151.

Colomba, C. "'Passagium generale: dal duello intellettuale alla lotta militare?", Itinerari di Ricerca storica, 20-21 (2008), pp. 89-98.

Colomer i Pous, E., “Autorretrato de Ramon Llull: Conversión y misión”, Pensamiento, 20 (1964), pp. 5-25.

Colomer i Pous, E., "Ramón Llull y el judaísmo en el marco histórico de la Edad Media hispana", EL, 10 (1966), pp. 5-45.

Colomer i Pous, E., "Ramón Llull y el judaísmo en el marco histórico de la Edad Media hispana (2)", EL, 12 (1968), pp. 131-144.

Colomer i Pous, E., "Ramón Llull y su actitud frente al Islam y al Judaísmo: del diálogo a la polémica", en Actas del V Congreso Internacional de Filosofía medieval, t. I. Editora Nacional, Madrid, 1979, pp. 631-639.

Colomer i Pous, E., "El pensament ecumènic de Ramon Llull”, en VV. AA., Miscel·lània Aramon i Serra: estudis de llengua i literatura catalanes oferts a R. Aramon i Serra en el seu setantè aniversari, t. III, Curial, Barcelona, 1983, pp. 61-80.

Colomer i Pous, E., "El pensament de Ramon Llull i els seus precedents històrics com a expressió medieval de la relació fe-cultura", en A. Bennàssar (ed.), Fe i cultura en Ramon Llull, Centre d'Estudis Teològics de Mallorca, Palma, 1986, pp. 11-29.

Colomer i Pous, E., “Ramón Llull y Ramón Martí”, EL, 28 (1988), pp. 1-37.

Colomer i Pous, E., "La actitud compleja y ambivalente de Ramon Llull ante el judaísmo y el islamismo", en F. Domínguez y J. de Salas (eds.), Constantes y fragmentos del pensamiento luliano. Actas del simposio sobre Ramon Llull en Trujillo, 17-20 septiembre 1994, Max Niemeyer Verlag, Tübingen, 1996, pp. 77-90.

Colomer I Pous, E., "El Diàleg interreligiós en Ramon Llull”, en íd. El Pensament als Països Catalans durant l'Edat Mitjana i el Renaixement, Publicacions de l'Abadia de Montserrat, Barcelona, 1997, pp. 113-179.

Colomer i Pous, E., "L'encontre de les religions en Ramon Llull”, Ars Brevis, no extraordinario (1998), pp. 101-112. 
Cortabarría Beitia, A., “Originalidad y significación de los Studia linguarum de los dominicos españoles de los siglos XIII y XIV”, Pensamiento, 25 (1969), pp. 71-92.

Cortabarría Beitia, A., "Connaissance de l'Islam chez Raymond Llull et Raymond Martin, OP. Parallèle”, Cahiers de Fanjeaux, 22 (1987), pp. 33-55.

Cortabarría Beitia, A., "Los «Studia Linguarum» de los dominicos en los siglos XIII y XIV”, en ed. C. del Valle Rodríguez, La controversia judeocristiana en España. (Desde los orígenes hasta el siglo XIII). Homenaje a Domingo Muñoz León, CSIC, Madrid, 1998, pp. 253-276.

Cruz Hernández, M., El pensamiento de Ramón Llull, Castalia, Valencia, 1977.

Cruz Hernández, M., "El símbolo del árbol en Ramón Llull e Ibn al-Jatîb”, en VV. AA., Studia Lullistica. Miscellanea in honorem Sebastiani Garcias Palou, Maioricensis Schola Lullistica, Palma, 1989, pp. 19-25.

Cruz Palma, Ó. de la (2008), "Man and society”, en A. Fidora y J. E. Rubio, Raimundus Lullus. An Introduction to his Life Works and Thought, Brepols, Turnhout, pp. 413-459.

Daniel, N., Islam and the West: The Making of an Image, Edimburgh University Press, Edimburgo, 1960.

Domínguez Reboiras, F., "Idea y estructura de la Vita Raymundi Lulli”, EL, 27 (1987), pp. 1-20.

Domínguez Reboiras, F., “«Moltes novelles raons». La originalidad del Ars praedicandi de Ramón Llull en su contexto medieval”, Anuario medieval, 4 (1992), pp. 93-137.

Domínguez Reboiras, F., "Ramon Llull, «catalán de Mallorca», y la lengua árabe. Contexto sociolingüístico”, en M. Aebi (ed.), Literatura i bilingüisme, Reichenberger, Kassel, 1993, pp. 3-17.

Domínguez Reboiras, F., "El proyecto luliano de predicación cristiana”, en F. Domínguez y J. de Salas (eds.), Constantes y fragmentos del pensamiento luliano. Actas del simposio sobre Ramon Llull en Trujillo, 17-20 septiembre 1994, Max Niemeyer Verlag, Tübingen, 1996, pp. 117-132.

Domínguez Reboiras, F., "Ramon Llull y la cruzada. Consideraciones preliminares a un tema controvertido", ROL, XXVIII (2003), pp. 257-322.

Domínguez Reboiras, F., "El discurso luliano de homine en el contexto antropológico coetáneo", en J. Corcó, A. Fidora, J. Olives y J. Pardo (eds.), Què és l'home?: reflexions antropològiques a la Corona d'Aragó durant l'Edat Mitjana, Prohom Edicions, Barcelona, 2004a, pp. 101-127.

Domínguez Reboiras, F., "El papa Nicolás IV, destinatario del Liber de passagio y Ramon Llull”, SL, 44 (2004b), pp. 3-15.

Domínguez Reboiras, F., "La idea de cruzada en el Liber de passagio de Ramón Llull”, Patristica et Mediaevalia, 25 (2004c), pp. 45-75. 
Domínguez Reboiras, F., "Works", en A. Fidora y J. E. Rubio (coords.), Raimundus Lullus. An Introduction to his Life Works and Thought, Brepols, Turnhout, 2008, pp. 125-242.

Domínguez Reboiras, F., "Una introducción a la vida, obra y pensamiento de Raimundo Lulio”, Anuario de Historia de la Iglesia, 19 (2010), pp. 383-388.

Domínguez Reboiras, F., "Raimundo Lulio y la Cruzada. Algunas reflexiones sobre su contexto histórico-teológico", Annales de philosophie, 33 (2012), pp. 33-57.

Domínguez Reboiras, F., "Dios, el mundo y el hombre según Ramon Llull”, Revista de Lenguas y Literaturas Catalana, Gallega y Vasca, 20 (2015), pp. 245-258.

Domínguez Reboiras, F., Ramon Llull. El mejor libro del mundo, Arpa Editores, Barcelona, 2016.

Domínguez Reboiras, F. y Gayà Estelrich, J., "Life", en A. Fidora y J. E. Rubio (coords.), Raimundus Lullus. An Introduction to his Life Works and Thought, Brepols, Turnhout, 2008, pp. 3-124.

DufourcQ, Ch.-E., "La Couronne d'Aragon et les Hafsides du Xlllè siècle”, $A S T$, 25 (1952), pp. 51-113.

DufourcQ, Ch.-E., "La Méditerranée et le Christianisme: cadre géopolitique et économique de l'apostolat missionaire de Ramon Llull', EL, 24 (1980), pp. 5-22.

EgeA I Ger, M., "Ramón Llull: del combate espiritual al combate por las armas", Revista agustiniana, 41 (2000), pp. 649-667.

EiJo Garay, L., "Las «rationes necessariae» del beato Ramon Llull en el marco de su época”, EL, 9 (1965), pp. 23-38.

EiJo Garay, L., “Las dignidades lulianas”, EL, 18 (1974), pp. 25-46.

ElíAs de TejadA, F., Las doctrinas políticas en la Cataluña Medieval, Aymá, Barcelona, 1950.

FidorA, A., "L'art de convertir allò que és probable en necessari: el pensament de Ramon Llull en el context del discurs filosòfico-apologètic del seu temps", Comprendre, 9 (2007), pp. 59-76.

FidorA, A., "Ramon Martí in context: the influence of the Pugio fidei on Ramon Llull, Arnau de Vilanova and Francesc Eiximenis", Recherches de Théologie et Philosophie Médiévales, 79 (2012), pp. 373-397.

Fidora, A. y Rubio, J. E. (coords.), Raimundus Lullus. An Introduction to his Life Works and Thought, Brepols, Turnhout, 2008.

Frediani, G., "Profili di Missionari: il B. Raimondo Lullo", Il Pensiero Missionario, 5 (1933), pp. 275-289.

García Fitz, F., "La Reconquista: un estado de la cuestión”, Clío y Crimen, 6 (2009), pp. 142-215. 
GARcía Fitz, F., "Crítica e hipercrítica en torno al concepto de reconquista. Una aproximación a la historiografía reciente", en C. de Ayala Martínez, I. C. Ferreira Fernandes y J. S. Palacios Ontalva (coords.), La Reconquista. Ideología y justificación de la Guerra Santa peninsular, La Ergástula, Madrid, 2019, pp. 79-98.

GARCÍA SANJuÁn, A., "La persistencia del discurso nacionalcatólico sobre el Medievo peninsular en la historiografía española actual”, Historiografías: revista de historia y teoría, 12 (2016), pp. 132-153.

García SAnjuÁn, A., "Rejecting al-Andalus, exalting the Reconquista: historical memory in contemporary Spain”, Journal of Medieval Iberian Studies, 10 (2018), pp. 127-145.

García SAnJuÁn, A., "Cómo desactivar una bomba historiográfica. La pervivencia actual del paradigma de la Reconquista", en C. de Ayala Martínez, I. C. Ferreira Fernandes y J. S. Palacios Ontalva (coords.), La Reconquista. Ideología y justificación de la Guerra Santa peninsular, La Ergástula, Madrid, 2019, pp. 99-119.

Garcías Palou, S., (1957), "San Anselmo de Canterbury y el Beato Ramón Llull”, EL, 1, pp. 63-89.

Garcías Palou, S., "Las «rationes necessariae» del beato Ramon Llull en los documentos presentados, por él mismo a la sede romana", EL, 6 (1962), pp. 311-325.

Garcías Palou, S., "El candidato de Ramón Llull para el cargo de «Maestro General» de la «Orden militar del Espíritu Santo»", EL, 16 (1972), pp. 63-77.

Garcías Palou, S., El Miramar de Ramon Llull, Instituto de Estudios Baleáricos-CSIC, Palma, 1977.

Garcías Palou, S., Ramón Llull y el islam, Gráficas Planisi, Palma, 1981.

GayÀ Estelrich, J. (ed.), Ars notatoria. CITEMA, Madrid, 1978.

GAYÀ Estelrich, J., “«De conversione sua ad poenitentiam»: reflexiones ante la edición crítica de Vita coetanea”, EL, 24 (1980), pp. 87-91.

GayÀ Estelrich, J., Ramon Llull, Ajuntament, Palma, 1982.

GayÀ Estelrich, J., "Ramon Llull, il suo impegno missionario", Analecta TOR, 32 (2001), pp. 379-388.

GayÀ Estelrich, J., "Introducción”, en Darrer llibre sobre la conquesta de Terra Santa, Proa, Barcelona, 2002, pp. 7-76.

GayÀ Estelrich, J., Raimondo Lullo. Una teologia per la missione, Jaca Book, Milán, 2002.

GayÀ Estelrich, J., "Ramon Llull i l'Islam. «Infideles sunt homines, sicut et nos»”, en 'Vós sou sant, Senyor Déu únic'. Franciscanisme i Islam. Jornades d'Estudis Franciscans, 2001, Facultat de Teologia de Catalunya, Barcelona, 2002, pp. 115-143. Texto disponible en <http://www.jordigaya2.eu/articulos/infideles.pdf > [10/04/2018].

GAYÀ Estelrich, J., "Una teologia de la història, com a premissa del diàleg intercultural proposat per Ramon Llull”, Comunicació. Revista del Centre d'Estudis Teolòics de Mallorca, 130 (2014), pp. 223-260. 
Giménez Reíllo, A., "El árabe como lengua extranjera en el s. XIII: medicina para convertir", El Saber en al-Andalus. Textos y Estudios, 4 (2005), pp. 147-187.

Goñi Gaztambide, J., Historia de la bula de cruzada en España, Publicaciones del Seminario, Vitoria, 1958.

Gottron, A., "Ramon Lulls Kreuzzugsideen", Abhandlungen zur mittleren und neueren Geschichte, 39 (1912): viii+96 pp.

Goyau, G., Figurines franciscaines, París, 1921.

Gracia, J. J. E., "La doctrina luliana de las razones necesarias en el contexto de algunas de sus doctrinas epistemológicas y sicológicas”, EL, 19 (1975), pp. 25-40.

Hames, H., "Quia nolunt dimittere credere pro credere, sed credere per intelligere: Ramon Llull and his Jewish Contemporaries", Mirabilia, 5 (2005), pp. 112-141.

Hillgarth, J. N., Ramon Lull and Lullism in Fourteenth-Century France, Clarendon Press, Oxford, 1971.

Hillgarth, J. N., "La vida i la significació de Ramon Llull”, Randa, 2 (1976), pp. 5-43.

Hillgarth, J. N., "Vida i importancia de Ramon Llull en el context del segle XIII", Anuario de Estudios Medievales, 26 (1996), pp. 967-978.

Hillgarth, J. N., Diplomatari lul·lià: documents relatius a Ramon Llull i a la seva família, Universitat de Barcelona / Universitat de les Illes Balears, Barcelona / Palma de Mallorca, 2001.

Housley, N., The Avignon Papacy and the Crusades, 1305-1378, Clarendon Press, Oxford, 1986.

JAULENT, E., "Mudança nos valores e a paz mundial segundo Raimundo Lúlio", Scintilla, Curitiba 10/1 (2013), pp. 169-181.

Johnston, M. D., "Ramon Llull and the Compulsory Evangelization of Jews and Muslims", en L. J. Simon (ed.), Iberia and the Mediterranean World of the Middle Ages. Studies in Honor of Robert Burns S. J., Brill, Leiden, 1995, pp. 3-37.

Kedar, B. Z., Crusade and Mission: European Approaches Toward the Muslims, Princeton University Press, Princeton, 1984.

Lavajo, J. Ch., "Un confronto metodológico no diálogo islamo-cristiano medieval. Raimundo Martí e Raimundo Lulo”, Revista de História das Ideas, 3 (1981), pp. 315-340.

LAVAJO, J. Ch., "The apologetical method of Raymond Marti according to the problematic of Raymond Lulle”, Islamochristiana, 11 (1985), pp. 155-176.

Llinarès, A., Raymond Lulle, philosophe de l'action, Presses Universitaires de France, París, 1963.

Longré, E., “Le B. Raymond Lulle et Raymond Martí, O.P.”, BSAL, 24 (1933), pp. 269-271 [reimpr. en EL, 13 (1969), pp. 197-200].

LONGPRÉ, E., "Deux opuscules inédits du B. Raymond Lulle", La France Franciscaine, 18 (1935), pp. 145-154. 
Lourido DíAz, R., "El estudio de la lengua árabe entre los franciscanos de Marruecos (siglos XIII-XVIII)", Archivo Ibero-Americano, 60 (2000), pp. 3-34.

LOwER, M., "Ibn al-Lihyani: sultan of Tunis and would-be Christian convert (1311-18)", Mediterranean Historical Review, 24 (2009), pp. 17-27.

Maier, C. T., Preaching the Crusades. Mendicant Friars and the Cross in the thirteenth Century, Cambridge University Press, Cambridge, 1994.

Marín i Torné, F.-X., “El diàleg islamocristià”, Ars Brevis, 5 (1999), pp. 341-364.

Marín I Torné, F.-X., "Religions en diàleg: Coneixement i comprensió per al segle XXI", Aloma, 10 (2002a), pp. 71-91.

Marín i Torné, F.-X., "Ramon Llull: Creure i entendre a través del diàleg”, Aloma, 11 (2002b), pp. 41-71.

Marín i Torné, F.-X., “L’islam i el diàleg interreligiós”, Ars Brevis, 9 (2003), pp. 100-120.

MARín I Torné, F.-X., "Un Mediterrani cosmopolita: el viatge de Ramon Llull a Orient”, Ars Brevis, 13 (2007), pp. 104-118.

MendíA, B., "En torno a las razones necesarias de la apologética luliana", Verdad y Vida, 8 (1950), pp. 385-421.

MietTA, L., "Un grande missionario del secolo XIII: il B. Raimondo Lulle”, Annuario Missionario Italiano, 1934, pp. 243-275.

Monneret de Villard, U., Lo studio dell'islam in Europa nel XII i nel XIII secolo, Biblioteca Apostolica Vaticana, Ciudad del Vaticano, 1944.

Moya, R. (ed.), Divi Raymundi Lulli Martyris Doctorisque Divinitus Illustrati Libellus de fine, Raphaelis Moya, Mallorca, 1665.

Musco, A. y Romano, M. M. M. (eds.), Il Mediterraneo del '300: Raimondo Lullo e Federico III d'Aragona, re di Sicilia. Omaggio a Fernando Domínguez Reboiras, Brepols, Turnhout, 2007.

Oliver, A., "Ramon Llull. Una tienda de encuentro para musulmanes y cristianos en el corazón del siglo XIII", Encuentro islamo-cristiano, 198 (1988), pp. 1-9.

PAllejÀ DE BustinzA, V., "Ramon Llull, genio filosófico, free lance y primera ONG unipersonal", Quaderns de la Mediterrània, 9 (2008), pp. 352-354.

Palma, A. de, "La doctrina jurídica i el sistema de dret internacional de Mestre Ramon Lull”, en VV. AA., Miscel·lània Patxot: estudis de dret public, Llibreria Verdaguer, Barcelona, 1931, pp. 407-432.

Palma, A. de, “El gran misionero medioeval: Ramón Lull”, Studia, 7 (1935), pp. 225230 y 281-285.

Palma, A. de, “Ramon Lull, pacificador”, Catalunya Franciscana, 14 (1936), pp. 14-16.

Palma, A. de, "El procurador de infieles", El Apostolado Franciscano, 28 (1941), pp. 43-44.

Palma, A. de, “Ramón Lull y la Sociedad de las Naciones”, EF, 49 (1948), pp. 229-260. 
Pardo Pastor, J., "En torno a las rationes necessariae del conocimiento de Dios: de Santo Tomás de Aquino a Ramon Llull”, Estudios Eclesiásticos, 77 (2002), pp. 461-475. Pardo Pastor, J., "Filosofía y teología en Ramón Llull: la Demonstratio per aequiparantiam", Revista Española de Filosofía Medieval, 9 (2002), pp. 265-274.

PARdo PAstor, J., “«Nisi crederitis, non intelligetis» (Is. 7,9) en la interpretación de Ramón Llull”, Patristica et Mediaevalia, 25 (2004), pp. 77-88.

PArdo PAstor, J., "Ramon Llull y el ars conuertendi: antropología, apologética, diálogo y hermenéutica”, Estudios Eclesiásticos, 80 (2005), pp. 69-94.

Perarnau i Espelt, J., "Un text català de Ramon Llull desconegut: la «Petició de Ramon Llull al papa Celestí V per a la conversió dels infidels». Edició i estudi”, ATCA, 1 (1982), pp. 9-46.

Perarnau i Espelt, J., "La Disputació de cinc savis de Ramon Llull. Estudi i edició del text català", ATCA, 5 (1986), pp. 7-229.

Perarnau i Espelt, J., "El Llibre contra Anticrist de Ramon Llull. Edició i estudi del text”, ATCA, 9 (1990), pp. 7-182.

Perarnau i Espelt, J., "La còpia manuscrita medieval de les tres lletres de Ramon Llull demanant al Rei, a un prelat de França i a l'Estudi de París l'establiment d'escoles de llengües (Clermont-Ferrand, BMI, ms. 96)", ATCA, 21 (2002), pp. 123-218.

Perarnau i Espelt, J., “Consideracions sobre el tema de Missió i croada en Ramon Llull dins publicacions recents", ATCA, 22 (2003), pp. 561-578.

Perarnau i Espelt, J., "Reseña de ROL XXVIII", ATCA, 23-24 (2004-05), pp. 546-551.

Perarnau i Espelt, J., “Certeses, hipòtesis i preguntes entorn el tema 'conversió i croada' en Ramon Llull. 'Croada militar' o ‘croada gramatical'?”, ATCA, 25 (2006), pp. 479-506. PINDL, T., "Ramon Llull, protagonista del diálogo intercultural”, Medievalia, 26 (1997), pp. 46-60.

Porsia, F., Progetti di crociata. Il De fine di Raimondo Lullo, Chimienti Editore, Taranto, 2005.

Puigdollers, M., "Doctrinas pacifistas de Raimundo Lulio en su relación con la comunidad internacional", Anales de la Universidad de Valencia, 6 (1925-26), pp. 208-222.

Purcell, M., Papal crusading policy 1244-1291, Brill, Leiden, 1975.

Richter, J., "Raymund Lullus. Ein Pionier der Mohammedaner-Mission", Allgemeine Missions-Zeitschrift, 42 (1915), pp. 387-394.

Romano, M. M. M. y Cruz Palma, Ó. de la, “The Human Realm”, en A. Fidora y J. E. Rubio, Raimundus Lullus. An Introduction to his Life Works and Thought, Brepols, Turnhout, 2008, pp. 363-459.

Roncaglia, M., "I frati minori e lo studio delle lingue orientali nel secolo XIII", Studi Francescani, 50 (1953), pp. 169-184.

Rousset, P., “La croisade obstacle à la misión”, Nova et vetera, 57 (1982), pp. 133-142. 
Roviró Alemany, I., "Ramon Llull y los Studia linguarum", en P. Hurtubise (ed.), Université, Église, Culture. L'Université Catholique au Moyen-Âge. Actes du $4^{\text {ème }}$ Symposium, Katholieke Universiteit Leuven, 11-14 mai 2005, Fédération Internationale des Universités Catholiques - Centre de Coordination de la Recherche, París, 2007, pp. 271-322. Runciman, S., "The Decline of Crusading Idea", en Relazioni del X Congresso internazionale di scienze storiche. Vol. 3: Storia del medioevo, G. C. Sansoni, Florencia, 1955, pp. 637-652.

Schein, S., Fideles Crucis. The Papacy, the West, and the Recovery of the Holy Land, 1274-1314, Clarendon Press, Oxford, 1991.

Siberry, E., "Missionaries and Crusaders, 1095-1274: Opponents or Allies?”, Studies in Church History, 20 (1983), pp. 103-110.

Siberry, E., Criticism of Crusading 1095-1274, Clarendon Press of Oxford University Press, Nueva York, 1985.

StöHr, J., "Las 'rationes necessariae' de Ramon Llull, a la luz de sus últimas obras", EL, 20 (1976), pp. 5-52.

Sugranyes de Franch, R., "Un texte de Ramón Lull sur la croisade et les missions", Nova et Vetera 21 (1946), pp. 98-112.

Sugranyes de Franch, R., Raymond Lulle Docteur des Missions. Avec un choix de textes traduits e annotés, Nouvelle Revue de Science Missionnaire, Schöneck-Beckenried, 1954.

Sugranyes de Franch, R., "Els projectes de creuada en la doctrina missional de Ramon Llull”, EL, 4 (1960), pp. 275-290.

Sugranyes de Franch, R., "La doctrina misional de Raimundo Lulio", Orbis catholicus, 3 (1960), pp. 296-310 [versión revisada y en castellano de id., "Els projectes..."; reed. en id., 1991: 13-28].

Sugranyes de Franch, R., "Ramon Llull i l'Islam”, Estudis Romànics, 10 (1962), pp. 17-31 [reed. en íd., 1991: 29-44].

Sugranyes de Franch, R., "Le «Libre du Gentil et des trois sages», de Raymond Lulle", Cahiers de Fanjeaux, 12 (1977), pp. 319-335.

Sugranyes De Franch, R., "L'apologétique de Raimond Lulle vis-à-vis de 1'Islam”, Cahiers de Fanjeaux, 18 (1983), pp. 373-393 [reed. en íd., 1991: 59-74].

Sugranyes de Franch, R., "Les propostes de Ramon Llull de modo convertendi infideles", en VV. AA., Studia Lullistica. Miscellanea in honorem Sebastiani Garcias Palou, Maioricensis Schola Lullistica, Palma, 1989, pp. 93-100.

Sugranyes de Franch, R., De Raimundo Lulio al Vaticano II (Artículos escogidos), Hispanica Helvetica 2, Lausanne, 1991.

Sugranyes de Franch, R., "La obra misional de Ramón Llull”, en Catalònia, 43 (1995), pp. 44-47 [v. divulg. de id. 1960a y 1960b]. 
Throop, P. A., Criticism of the Crusade: A Study of Public Opinion and Crusade Propaganda, N. V. Swets \& Zeitlinger, Amsterdam, 1940.

Tolan, J. V., Saracens: Islam in the Medieval European Imagination, Columbia University Press, Nueva York, 2002.

Trías Mercant, S., Ramón Llull. El pensamiento y la palabra, El Tall, Palma, 1993.

Trías Mercant, S., "Las claves hermenéuticas del pensamiento de Ramón Llull”, Revista Española de Filosofía Medieval, 4 (1997), pp. 51-64.

Trías Mercant, S., "Judíos y Cristianos: La Apologética de la Tolerancia en el «Llibre del Gentil»”, Revista Española de Filosofía Medieval, 5 (1998), pp. 61-74.

URmenEta, F. de, “El pacifismo luliano”, EL, 2 (1958), pp. 197-208.

Urvor, D., "Les Musulmans et l'usage de la langue arabe par les missionaires chrétiens au moyen-âge", Traditio, 34 (1978), pp. 416-427.

Unvoy, D., Penser l'Islam. Les présupposés islamiques de l'«Art» de Lull, Vrin, París, 1980.

URvoY, D., "Les musulmans pouvaient-ils comprendre l'argumentation lullienne?", Estudi General, 9 (1989), pp. 159-170.

Valls, G., "L'ideale missionario del B. Ramon Lull”, Studi Francescani, 12 (1926), pp. 117-128.

VAlls i TABerner, F., "La Societat de les Nacions i les idees de comunitat internacional en els antics autors catalans", La Paraula Cristiana, 1 (1925), pp. 13-29.

Vega Esquerra, A., Ramon Llull y el secreto de la vida, Siruela, Madrid, 2002.

Villalba i Varneda, P., Ramon Llull, Escriptor i filòsof de la diferència. Palma de Mallorca, 1232-1316, Universitat Autònoma de Barcelona, Bellaterra, 2015.

WAlter, P., "C'è un messsaggio di Raimondo Lullo per oggi?", en L. BAdiA-A. FidorAM. Ripoll (eds.), Actes del Congrés d'Obertura de l'Any Llull. En el seté centenari de Ramon Llull: el projecte missional i la pervivència de la devoció, Barcelona, 2017, pp. 15-31.

Wheeler, L. A., The Problem of the Saracen Infidel: Crusade Proponents and Critics from Bacon to Piloti [MA Thesis], McGill University, Montreal, 1981.

Wieruszowski, H., "Ramon Lull et l'idée de la cite de Dieu: Quelques nouveaux écrits sur la croisade", EF, 47 (1935), pp. 87-110 [reed. en íd., Politics and Culture in Medieval Spain and Italy, Edizioni di Storia e Letteratura, Roma, 1971, pp. 147-171].

Zwemer, S. M., Raymund Lull. Fist Missionary to the Moslems, Funk \& Wagnalls Company, Nueva York / Londres, 1902. 
